\title{
Employee Attributions of the "Why" of HR Practices: Their Effects on Employee Attitudes and Behaviors, and Customer Satisfaction
}

\author{
Lisa H. Nishii \\ David P. Lepak \\ Benjamin Schneider
}

Working Paper 08 - 03 


\title{
Employee Attributions of the "Why" of HR Practices: Their Effects on Employee Attitudes and Behaviors, and Customer Satisfaction
}

\author{
Lisa H. Nishii \\ Department of Human Resource Studies \\ School of Industrial and Labor Relations \\ Cornell University \\ 393F Ives Hall \\ Ithaca, NY 14853 \\ Tel: (607) 255-4431 \\ Fax: (607) 255-1836 \\ Email: LHN5@cornell.edu
}

\section{David P. Lepak}

Rutgers, The State University of New Jersey

School of Management and Labor Relations

Department of Human Resource Management

Piscataway, NJ 08854

Tel: (732) 445-5824

Fax: (732) 445-2830

E-mail: lepak@smlr.rutgers.edu

\section{Benjamin Schneider}

Valtera and the University of Maryland

1363 Caminito Floreo, Suite G

La Jolla, CA 92037

Tel and fax: (858) 488-7594

E-mail: bschneider@valtera.com

February 2008

http://www.ilr.cornell.edu/cahrs

This paper has not undergone formal review or approval of the faculty of the ILR School. It is intended to make results of Center research available to others interested in preliminary form to encourage discussion and suggestions.

Most (if not all) of the CAHRS Working Papers are available for reading at the Catherwood Library. For information on what's available link to the Cornell Library Catalog:

http://catalog.library.cornell.edu if you wish. 


\begin{abstract}
The construct of Human Resource (HR) Attributions is introduced. We argue that the attributions that employees make about the reasons why management adopts the HR practices that it does have consequences for their attitudes and behaviors, and ultimately, unit performance. Drawing on the strategic HR literature, we propose a typology of five HRAttribution dimensions. Utilizing data collected from a service firm, we show that employees make varying attributions for the same HR practices, and that these attributions are differentially associated with commitment and satisfaction. In turn, we show that these attitudes become shared within units and that they are related to unit-level organizational citizenship behaviors and customer satisfaction. Findings and implications are discussed.
\end{abstract}

\title{
ACKNOWLEDGEMENT.
}

We would like to thank Michele Gelfand, Paul Tesluk, Paul Hanges, and John Hausknecht for their invaluable feedback on earlier drafts of this paper. This research was funded by a grant from the National Science Foundation. 


\section{Employee Attributions of the "Why" of HR Practices: Their Effects on Employee Attitudes and Behaviors, and Customer Satisfaction}

\section{Introduction}

Strategic human resources management (SHRM) researchers have sought to understand the ways in which a firm's human resource $(H R)$ practices are associated with its performance, and they have amassed impressive research on the topic over the last two decades. Research has generally supported the notion that when appropriately designed, HR practices can help organizations enhance their performance. However, as Wright and Nishii (in press) note, this research has contributed little to our theoretical understanding of how HR practices and performance relate; much more research that examines variables that might be involved in the proverbial "black box" between HR systems and organizational performance is needed (Bowen \& Ostroff, 2004; Nishii \& Wright, in press; Ostroff \& Bowen, 2000). Although scholars have converged in their belief that HR practices are associated with organizational outcomes through their influence on employee attitudes and behaviors (e.g., Huselid, 1995; Wright, McCormick, Sherman, \& McMahan, 1999; Wright, McMahan, \& McWilliams, 1994), Bowen and Ostroff (2004), and Nishii and Wright (in press; Wright \& Nishii, in press) have recently suggested that the causal chain may be more complex than previously thought. They suggest that employees' perceptions of HR practices are likely to precede the employee attitudes and behavior links in the causal chain. That is, in order for HR practices to exert their desired effect on employee attitudes and behaviors, they first have to be perceived and interpreted subjectively by employees in ways that will engender such attitudinal and behavioral reactions. But if, as we know from psychological research, people perceive reality differently (Ichheiser, 1949; Fiske \& Taylor, 1992), then we can expect that not all employees will interpret HR systems similarly. This suggests that the effect of HR practices is not likely to be automatic and always as expected; instead, their effect will reside in the meanings that employees attach to those practices.

Despite the intuitive appeal of such arguments, however, the oft-used study designs, in which managerial reports of HR practices are linked to measures of organizational performance, 
have not allowed for an examination of the ways in which individuals may experience and respond differentially to HR systems within organizations (cf. Gerhart, Wright, \& McMahan, 2001). Thus, empirical research which begins to explore the role of employees' perceptions of HR practices in the causal chain is sorely needed (Wright \& Nishii, in press).

In one of the most comprehensive theoretical models on the topic to date, Bowen and Ostroff (2004) argue that in order for a HR system to link to performance in desired ways, it must elicit unambiguous and shared perceptions of climate, or the behaviors that management expects, supports, and rewards. Their work is groundbreaking in their acknowledgement of the role employee perceptions play in translating HR practices into desired organizational outcomes. We build on their theory by also proposing that employees' perceptions of HR practices are important. However, our focus diverges from theirs on climate because we focus not on employees' perceptions about what HR practices connote with regard to the behaviors that are expected, supported, and rewarded by management, but rather on employees' attributions for why the HR practices exist. It is possible for employees to share climate perceptions based on the HR practices they experience - for example that safety-focused behaviors are expected and rewarded (i.e., climate for safety, Zohar, 1980) - but to disagree about why those HR practices were put into place to create that climate. It could be that some employees perceive that the creation of a safety climate is motivated by management's concern for employee well-being, while others perceive it to be motivated by a desire to cut costs associated with accidents on the job, or by external requirements imposed by regulatory bodies.

The core idea in our research is that employees respond attitudinally and behaviorally to HR practices based on the attributions they make about management's purpose in implementing the actual HR practices. While some research attention has been paid to the desired attitudinal and behavioral reactions to HR practices (e.g., commitment, satisfaction, discretionary behaviors, productivity, absenteeism), little attention has been paid to employees' attributions about the why of specific HR practices, the attributions upon which the attitudinal and behavioral reactions are likely based (see Koys, 1988, 1991 for exceptions). According to 
social attribution theory, people can attach different meanings to social stimuli (Fiske \& Taylor, 1991), and based on the way that they process these stimuli, their attitudinal and behavioral responses to that information may differ. When this logic is applied to the study of HR practices, it follows that the relationship between HR practices and employee attitudes and behaviors, and ultimately organizational performance, may depend on the attributions employees make about the motives underlying the HR practices they experience. As we describe below, we differentiate between two internal HR attributions that are expected to relate positively to employee attitudes (i.e., the attributions that HR practices are designed due to management's intent to enhance service quality and employee well-being), and two that are expected to relate negatively to employee attitudes (i.e., the attributions that HR practices are designed due to management's interest in cost reduction and exploiting employees), as well as between these internal HR attributions and an external attribution that HR practices are designed in response to situational pressures that are external to management (i.e., the attribution that HR practices are designed to comply with union requirements).

Given previous attention to satisfaction, commitment, and organizational citizenship behaviors (OCBs) as representing desired employee responses to HR practices (e.g., Arthur, 1992, 1994; Huselid, 1995; Jackson \& Schuler, 1995; Tsui, Pearce, Porter, \& Tripoli, 1997), we focus in this study on the relationships between HR Attributions and satisfaction and commitment at the individual-level of analysis. Consistent with past research, we further propose that while satisfaction and commitment are attitudes that originate at the individual-level of analysis, they become shared among unit members through a number of social processes (Ostroff, 1992). These emergent unit-level attitudes in turn influence unit-level OCBs and valued performance outcomes; in the current study, we focus on customer satisfaction. There are two possible ways to test the proposed conceptual links involving HR Attributions. The first is to examine the relationship between HR practices, HR Attributions and outcome variables across firms. The second is to examine the effect of HR Attributions on firm performance across units within an organization-as long as equivalent performance measures are available 
across all units. We chose the latter approach for the current study because it allows us to hold HR practices, executive leadership, and other important organizational context factors relatively constant across units of analysis, thereby making HR Attributions the focus of the study. The organization that participated in our research was chosen precisely because it is structured around departments as the unit of analysis, has enough departments to enable meaningful within-organization tests of the proposed relationships, and consistent customer satisfaction data across departments were available.

\section{Theoretical Background and Hypotheses}

Research on causal attributions has a long history, dating back to early work by Heider (1958), Jones and Davis (1965), and Kelley (1967), and voluminous subsequent work conducted by psychologists and by scholars from other disciplines who applied attribution theory to their specific areas of inquiry. Attribution theory is primarily concerned with the generic causal principles that people use to explain people's behavior or events, whereas attributional theories are concerned with specific attributions that people make in a particular life domain. The distinction is important because though attributional theories draw inspiration from attribution theory, attribution theory as originally developed describes generic, content-free processes that rarely apply to the attributional processes that actually unfold in specific content domains wherein people utilize domain-specific knowledge structures to guide the attribution process rather than content-free attributional principles (Hilton \& Slugoski, 1986). Thus, while some of the basic building blocks of attribution theory may be useful for thinking about attributions of HR practices, others are not. This is particularly true because attribution theory focuses on causal explanations for one's own behavior, others' behavior, or episodic events, whereas our construct of HR attributions refers to employees' causal explanations for HR practices to which they are exposed on an ongoing basis. Thus, many of the principles which help explain the way people arrive at causal explanations for behavior or episodic events do not generalize to the case of HR attributions. Indeed, Lord and Smith (1983) cautioned researchers from over-generalizing attribution theories to organizational research, and urge scholars to build 
context-specific attributional models instead. Nevertheless, we first describe some of the main principles of generic attribution theory before turning to the more specific case of our attributional theory of HR practices.

\section{Causal Attributions}

Early theorists in this area proposed that people have a basic need to predict and control the environment, and that understanding the causes of behaviors and/or events helps people to do so (Heider, 1958). Furthermore, they argued that understanding attributions is critical because people's interpretations of the causes of behavior and events determine their subsequent attitudes and behaviors (Kelley \& Michela, 1980). According to Heider (1958), one of the fundamental considerations for explaining why someone behaved as he or she did is whether the locus of causality is internal or external to the person (i.e., dispositional or environmental). When the behavior is thought to have been caused by dispositional factors, the behavior is more informative, and is believed by perceivers to be a more reliable predictor of future behavior (Jones \& Davis, 1965). Therefore, internal attributions tend to be more strongly associated with other cognitions, feelings, and behavior (Jones, et al., 1972; Weiner et al., 1972) than external attributions, which, according to the discounting rule, reveal less about the underlying motivation of the behavior (Kelly \& Michela, 1980). Other factors are also thought to influence the impact of attributions on associated attitudes and behaviors. For example, observed behavior is thought to be more informative as it decreases in social desirability, because when observed behaviors are socially desirable, there is a greater chance that the behavior represents the constraints of the situation (i.e., influence of norms or social expectations) rather than some aspect of the actor's choice or disposition (Jones, Davis, \& Gergen, 1961; Jones \& McGillis, 1976). Also, the more stable one perceives the cause of a behavior or event to be (i.e., whether it is likely to change in the future), the more pronounced the effect of that behavior/event, and the more an observer perceives the actor as having control over the behavior/event, the stronger the resulting effect (Weiner, 1979). 


\section{A model of HR Attributions}

We define HR Attributions as causal explanations that employees make regarding management's motivations for using particular HR practices, and argue that employees' HR attributions have important consequences for their commitment and satisfaction. Consistent with existing attribution theories (e.g., (Hdier, 1958; Jones \& Davis, 1965), we first distinguish between internal and external HR attributions, since external attributions have been found to be less influential for observer attitudes and behaviors than internal attributions. In some earlier work, Koys $(1988,1991)$ also differentiated between internal and external causal explanations for HR practices. He suggested that HRM activities that are done "out of a spirit of justice" or "to attract and retain employees" at their companies represented internal attributions, while perceptions that HRM activities were done to "encourage individual or organizational performance" or "to comply with government relations" were examples of external causal explanations. Although it is unclear why Koys chose this particular set of causal explanations to study, and why "to encourage individual or organizational performance" represents an external attribution, his empirical results largely confirmed the hypothesis that internal causal explanations are positively related to commitment while external causal explanations are unrelated to commitment.

We build on Koys' $(1988,1991)$ work by also making a distinction between internal and external HR attributions, but beyond this distinction, we argue that internal attributions are likely to be multi-dimensional. In order to develop a typology of internal HR attributions, we turned to the SHRM literature to identify the often discussed causes for why management adopts the HR practices that it does. Two main themes, which differ from those proposed by Koys (1988, 1991), emerged as being particularly relevant. The first involves the strategic or businessrelated goals that underlie HR practices. The SHRM literature is replete with discussions concerning the distinction between "quality enhancement" and "cost reduction" strategies (e.g., Arthur, 1992, 1994; Porter, 1980; Schuler \& Jackson, 1987), with the assumption being that employers adopt HR practices that are most likely to channel employee attitudes and behaviors 
to be aligned with the business strategy (Jackson \& Schuler, 1995). Therefore, we include HR attributions reflecting the "service quality enhancement" and "cost reduction" strategic foci in our typology. Second, SHRM researchers have also differentiated HR systems based on the underlying employee-oriented philosophy held by management (e.g., Lepak, Taylor, Tekleab, \& Marrone, 2002; Osterman, 1994). A philosophy aimed at maximizing employee well-being has been differentiated from a philosophy aimed at maximizing employee efficiency. Thus, we include HR attributions related to each of these philosophies in our typology, depicted in Table 1. It is important to note that while managerial reports of both the strategic goals and employeeoriented philosophies underlying HR practices have been examined, research has yet to focus on employees' perceptions of the extent to which these factors motivate HR practices, and thus our focus on employees' HR attributions related to these themes represents a novel contribution to existing SHRM research.

\section{Table 1}

Typology of HR Attributions

\begin{tabular}{|c|c|c|c|}
\hline & \multicolumn{2}{|c|}{ Internal Attributions } & \multirow[b]{2}{*}{$\begin{array}{l}\text { External } \\
\text { Attribution }\end{array}$} \\
\hline & $\begin{array}{c}\text { Business/strategic } \\
\text { goal underlying HR }\end{array}$ & $\begin{array}{c}\text { Employee-oriented } \\
\text { Philosophy }\end{array}$ & \\
\hline $\begin{array}{l}\text { Commitment- } \\
\text { Focused }\end{array}$ & Service quality & $\begin{array}{c}\text { Employee } \\
\text { Well- Being } \\
\end{array}$ & \multirow{2}{*}{ Union Compliance } \\
\hline Control-Focused & Cost Reduction & $\begin{array}{l}\text { Exploiting } \\
\text { Employees }\end{array}$ & \\
\hline
\end{tabular}

As shown in the columns of Table 1, both the HR Attributions regarding the business goals and employee-oriented philosophies underlying HR practices are internal attributions, which refer to the perception that actions are due to factors for which the actor (management) is responsible, or over which the actor has control. In contrast, an external attribution would be one in which management is perceived as a passive recipient of external, environmental, forces (i.e., the perception that HR practices are adopted not as a function of management's voluntary intentions but because management has to adopt certain HR practices due to external constraints). Constraints mandated by union contracts may be the most common and salient for 
unionized employees, although other possibilities include EEO laws and institutional norms (i.e., the pressure to conform to HR practices being offered by competing organizations).

Turning to the rows in Table 1, we expect internal attributions to be differentiable based on whether they connote positive or negative implications for employees, with the expectation that the underlying valence of these attributions will dictate their relationship with employees' attitudinal responses. Indeed, early attribution theory suggests that the "hedonic relevance" of a behavior (i.e., HR practice) for an observer (i.e., employee) influences the attributions that are made, such that behaviors that are perceived to benefit the perceiver result in favorable attributions, whereas behaviors that have adverse effects for the perceiver lead to unfavorable attributions (Jones \& Davis, 1965). In line with social exchange principles, we expect that commitment-focused (e.g., Arthur, 1992; 1994) HR Attributions that connote positive consequences for employees (i.e., Service Quality and Employee well-being HR attributions) are likely to engender a felt obligation to reciprocate in positive and beneficial ways (cf. Ostroff \& Bowen, 2000; Schmit \& Allscheid, 1995; Whitener, 2001). However, when employees perceive that the intended goals of HR practices connote lower levels of concern for employees and a more cost-driven control-focus (i.e., Cost Reduction and Exploiting Employees HR attributions), lower levels of satisfaction and commitment are likely to ensue.

\section{HR Attributions Regarding HR Strategy}

As mentioned previously, there has been significant attention paid to the distinction between "quality enhancement" strategies and "cost reduction" strategies within the SHRM literature (e.g., Arthur, 1992, 1994; Porter, 1996: Schuler \& Jackson, 1987). Consistent with the resource-based view of the firm, scholars have argued that when a firm adopts a quality enhancement HR strategy in which employees are perceived as assets required to produce high quality goods/services, large investments tend to be made in the long-term development of employee skills, management focuses on motivating employees to work hard toward qualityoriented goals, and management places the importance of employee welfare above revenues and profits (Schuler \& Jackson, 1987). In contrast, when the strategic focus is on competing on 
the basis of low costs, management perceives employees as costs to control, focuses on enforcing employee compliance with rules and procedures, and monitors the quantity of employee output (Bamberger \& Meshoulam, 2000). Under the latter circumstances, employees are seen as replaceable workers who are part of a cost equation function and the associated HR strategy tends to focus on reducing costs associated with each employee by, for example, offering low base salaries with few perks and engaging in narrow and short-term training (Schuler \& Jackson, 1987).

However, past work on these HR strategies has focused on the employer's perspective. We build on this work by focusing on employees' attributions regarding the HR strategy that they perceive as motivating specific HR practices. We expect that any HR practice can be viewed differently by employees in a single firm such that some employees perceive an HR practice as connoting an underlying quality HR strategy and others attribute the practice to a cost reduction HR strategy, regardless of the actual HR strategy pursued by management. For example, to some employees, a pay for performance system might communicate an underlying motivation of management to empower employees and encourage them to produce high quality products or services, and a willingness to reward employees according to their worth (Spreitzer, 1995). Such employees might make the attribution that their firm's pay practices are motivated by a quality enhancement HR strategy. To other employees in the firm, however, the same pay for performance practice might be perceived as a means of controlling costs by getting the most employee productivity per dollar spent on labor costs (Deckop, Mangel, \& Cirka, 1999). They might perceive that it is a means for management to closely monitor performance, and that compared to pay structures in which all employees of a given tenure and rank receive roughly the same pay regardless of performance, pay for performance ensures little waste for the organization. Such employees would likely make the attribution, then, that their firm's pay practices are motivated by a cost reduction HR strategy. This example illustrates how the same HR practices may be viewed differently by employees, even within the same firm. 
Thus, from an employee perspective, we draw a parallel to the commitment/control distinction within the strategic HR literature and anticipate that employees will interpret the extent to which they perceive HR practices as signaling an underlying Quality HR strategy in which employees are viewed as an asset, versus a Cost Reduction HR strategy in which employees are viewed as a cost to be controlled. We expect the extent to which employees attribute these different HR strategic priorities to their company to logically be associated with their attitudes on the job. The more employees perceive that they are viewed as assets by their employers, the more they are likely to be willing, in turn, to give back to their employers in the form of commitment to the organization (Eisenberger, Fasolo, \& Davis-LaMastro, 1990).

Hypothesis 1: Attributions that HR practices reflect a Quality HR Strategy will be positively related to employee commitment and satisfaction.

However, we expect that when employees perceive that HR practices reflect an underlying Cost Reduction HR strategy in which the organization views employees as a cost to be minimized, corresponding levels of commitment and satisfaction will be negative (Appelbaum, LavigneSchmidt, Peytchev, \& Shapiro, 1999).

Hypothesis 2: Attributions that HR practices reflect a Cost Reduction HR Strategy will be negatively related to employee commitment and satisfaction.

\section{HR Attributions Regarding Management's Employee-Oriented Philosophy}

In addition to focusing on HR strategies, SHRM scholars have begun to differentiate HR systems based on the underlying HR philosophy held by management (Lepak, Taylor, Tekleab, Marrone, \& Cohen, 2002; Osterman, 1994). According to strategic choice theory (Child, 1972; 1997), managers' decisions are influenced not only by their company's strategy and environmental pressures, but also by their ideology and philosophical values regarding how employees should be managed. For example, Osterman (1994) found that establishments that believe that they have a responsibility for enhancing employee welfare were more likely to adopt innovative work practices targeted at enhancing employee skills, commitment and motivation rather than at reducing financial costs. Similarly, Lepak and colleagues (2002) argued and 
found that while business strategy is a likely determinant of the adoption of high performance work practices, a firm's employee-oriented philosophy—specifically whether employees are viewed as an asset or as costs to be controlled-is a more proximal determinant of HR decisions.

Again, however, HR philosophies have to date been examined only from the employer's perspective, and we focus instead on the employees' perspective. It is reasonable to expect that employees perceive and evaluate management's HR philosophies, and that their attributions regarding management philosophy influence the nature of the employer-employee relationship. Specifically, we expect that when employees perceive that specific HR practices are motivated by an underlying managerial philosophy of caring for employee well-being, then those employees will feel more satisfied and committed than if they perceive that management cares less about their well-being (cf. Eisenberger, et al., 1990; shore \& Wayne, 1993). Thus, we expect:

Hypothesis 3: Employee attributions that HR practices reflect a managerial philosophy that is focused on Employee Well-being will be positively related to employee commitment and satisfaction.

In contrast to the expected positive effects of HR Attributions regarding employee wellbeing, the attribution that HR practices are motivated primarily by a managerial philosophy focused on exploiting, or getting the most out of employees, is likely to have negative effects on employee attitudes. Implicit in this attribution is the notion that by virtue of being focused on getting the most out of employees, management may not always have the interests of employees at heart. Employees who hold this view are likely to believe that unless investments in employees are associated with cost or efficiency savings, management will be reluctant to adopt them. Such a view is indicative of a perceived lack of intrinsic management commitment to employee development and welfare, and thus will likely be reciprocated with correspondingly lower levels of employee commitment and satisfaction. Accordingly, we expect: 
Hypothesis 4: Employee attributions that HR practices reflect a managerial philosophy that is focused on Exploiting Employees will be negatively related to employee commitment and satisfaction.

\section{External Attribution: Union Compliance}

As mentioned previously, the external attribution of interest in our study is the attribution that HR practices are designed in response to legal requirements, specifically in response to union requirements. We expect that external attributions, such as the perception that the design of HR practices is a function of union requirements, will exhibit a non-significant relationship with employee attitudes for a number of reasons. First, as argued by early attribution theorists (e.g., Jones \& Davis, 1965), external/situational explanations are less helpful for predicting future behavior or events than internal explanations because they are more easily subject to change than enduring internal dispositions. In addition, because compliance with union requirements is socially desirable, it provides little information about the underlying dispositional traits or values of management (Jones \& McGillis, 1976) and therefore is unlikely to be related to other cognitions or behaviors on the part of employees. Furthermore, as Weiner (1979) might argue, because compliance with union requirements may be perceived as an unstable and to some extent uncontrollable cause of behavior - because union contracts are subject to change and are subject to influence from parties other than management - the attribution that concern for union compliance drives the design of HR practices should not have a pronounced effect on associated employee attitudes. Taken together, past research findings suggest that the external HR attribution that HR practices are motivated by management's concern to comply with union requirements should be unrelated to employee satisfaction and commitment.

Even if employees were to attribute meaningful dispositional explanations to management's efforts to comply with union requirements, both positive and negative causal explanations are possible, and thus we expect the net effect across employees to be nonsignificant. In some cases, employees may view management's concern for union compliance as a signal that management values employee rights; as a result, those employees may 
respect, appreciate, and value management, thereby making their Union Compliance HR attribution positively related to employee attitudes. In other cases, employees may perceive that management's efforts to comply with union requirements suggests that management cares only about doing the bare minimum to avoid legal liability, but nothing more. In other words, it is possible for employees to have either an optimistic or cynical view of management's commitment to union compliance. In much the same way that empowerment and participation practices in the automotive industry have been simultaneously viewed as "empowerment" or "exploitation" (whereby more is demanded of workers without concomitant increases in resources) by employees within a single organization (Babson, 1995), we too believe that the same HR attribution regarding union compliance can take on differential meanings within a single organization. It is for this reason that we expect an overall null relationship between this attribution and employee attitudes (because the positive and cynical perceptions cancel each other out). This is consistent with research which has found that there is no consistent effect of union membership on employee satisfaction (Gordon \& Denisi, 1995). Therefore,

Hypothesis 5: Employee attributions that HR practices reflect a concern for Union Compliance will be unrelated to employee commitment and satisfaction.

\section{Satisfaction, Commitment, and OCBs}

A goal of $H R$ is to impact individual attitudes and behaviors so that in the aggregate, unit and organizational performance are also enhanced; here, we focus on the effects of aggregate satisfaction and commitment on unit level customer satisfaction. Although the overwhelming majority of research on employee satisfaction and commitment has occurred at the individuallevel of analysis, scholars have more recently begun to recognize that even employee attitudes such as satisfaction and commitment, which originate within individuals and therefore were assumed to be idiosyncratic, become shared by employees in work units (Harter, Schmidt, \& Hayes, 2002; Currall, Towlwer, Judge, \& Khon, 2005; Ostroff, 1992; Schneider, Hanges, Smith, \& Salvaggio, 2003). We expect these attitudes to become shared among members of the same work unit for a number of reasons. First, unit members are likely to be exposed to a variety of 
unit goals, rules and procedures, strategies, technologies, work environments, task demands, and leadership that lead to shared experiences and attitudes, which are differentiable from those of unit members in other groups. Thus, employees' attitudes are likely to be influenced, at least in part, by factors that are shared across unit members, and which therefore account for a significant portion of shared attitudes. Second, through what Moregeson and Hoffman (1999) term the process of "double interact," unit members come to share their attitudes and views of the organization. In essence, when an employee shares some sentiment with a colleague, who responds, the first employee responds back, and this reciprocal interaction creates collective perceptions. Third, once a unit has established a distinct character, attraction-selection-attrition dynamics (Schneider, 1987) may further accentuate similarity in attitudes across employees.

Further, we expect unit-level commitment and satisfaction will be positively associated with OCBs. Given that committed employees feel emotional attachment to the organization, it follows that they will have a greater motivation or desire to contribute behaviorally to the organization than would employees with negative affective commitment (Meyer \& Allen, 1997). Similarly, satisfaction is an important predictor of OCBs, as theory suggests that whether employees give their efforts wholeheartedly to the organization and produce up to their potential depends in large part on the way they feel about their jobs and work environment (Judge, Thoresen, Bono, \& Patton, 2001; Ostroff, 1992). In support of these relationships, recent metaanalyses on OCBs revealed that overall job satisfaction and organizational commitment consistently predict OCBs, and that they are among the strongest attitudinal predictors of OCBs (with correlations in the .30 range; Organ, Podsakoff \& MacKenzie, 2005). Although these meta-analyses focused on individual-level relationships, it is reasonable to expect that similar relationships would hold at the group level of analysis (Ostroff, 1992; Ehrhart \& Naumann, 2004).

Hypothesis 6: Unit-level satisfaction and commitment will be positively related to OCBs across units. 


\section{Performance Outcomes}

Clearly, an ultimate goal for organizations is to enhance performance in the marketplace, often measured in terms of productivity, profits, or customer satisfaction. For service companies, one of the keys to making profits is satisfying one's customers (Anderson, Fornell, \& Lehman, 1994; Rust \& Zahorik, 1993). This has been substantiated by studies showing a clear relationship between service quality, customer satisfaction, and financial returns (e.g., Hallowell, 1996; Nelson, Rust, Zahorik, Rose, Batalden, \& Siemanski, 1992; Schneider, Ehrhart, Mayer, Saltz \& Niles-Jolly, 2005). An impressive research stream has shown that customers' experiences of service quality are influenced by employees' experiences, specifically by their attitudes and behaviors (e.g, Schneider \& Bowen, 1995; Schneider, Wheeler, \& Cox, 1992). As stated by Rucci and his colleagues (Rucci, Kirn, \& Quinn, 1997), "any person with even a little experience in retailing understands intuitively that there is a chain of cause and effect running from employee behavior to customer behavior to profits, and it's not hard to see that behavior depends primarily on attitude (Rucci, et al., 1998; p.84). Thus, it is reasonable to expect that employees' attitudes, and in turn OCBs, will be associated with customer satisfaction.

Researchers have focused on OCBs as being important in influencing performance because spontaneous, cooperative behaviors on the part of employees that may go beyond their formal work requirements are necessary for the accomplishment of organizational goals (Katz \& Kahn, 1966). Consistent with Katz and Kahn's (1966) claim, researchers have proposed that the difference between outstanding and mediocre service companies is that in the former, employees exert more discretionary effort and engage in organizational citizenship behaviors that favorably influence customers' perceptions of service quality (Berry, 1999; Bowen, Schneider, \& Kim, 2000; Morrison, 1997). OCBs are particularly important for customer satisfaction because the often unpredictable nature of services makes it difficult to specify beforehand the behaviors that are necessary for producing high quality service (Morrison, 1996); thus, many employee behaviors that are necessary for producing high quality service fall outside the formal job requirements of employees and are instead discretionary OCBs. Further, 
Podsakoff and his colleagues (2000) suggest that OCBs enhance customer satisfaction at the unit level when employees help each other with work-related problems, thereby freeing the manager to spend more time on other productive tasks. Support for the expected relationship between OCBs and customer satisfaction has been empirically examined in a handful of studies. In a study of a restaurant chain, Koys (2001) found that OCBs at the unit level correlated .36 with service quality for that unit, and Schneider and his colleagues (2005) found a .28 relationship between OCBs and unit customer satisfaction in chain of supermarkets. A meta-analysis of OCBs by Podsakoff, MacKenzie, Paine, and Bachrach (2000) suggests an even stronger relationship, with OCBs accounting for roughly $38 \%$ of the variance in customer satisfaction indicators. Thus, accordingly, we expect:

Hypothesis 7: Unit-level OCBs will be positively associated with unit performance. The relationships proposed in hypotheses 1-7 can be seen graphically in Figure 1. As shown, the individual level HR Attributions are expected to be correlated with individual attitudes and commitment. In the aggregate, unit level satisfaction and commitment are expected to be positively associated with OCBs, which will be positively related to customer satisfaction. 
Figure 1:

The hypothesized model

Individual

- level of analysis

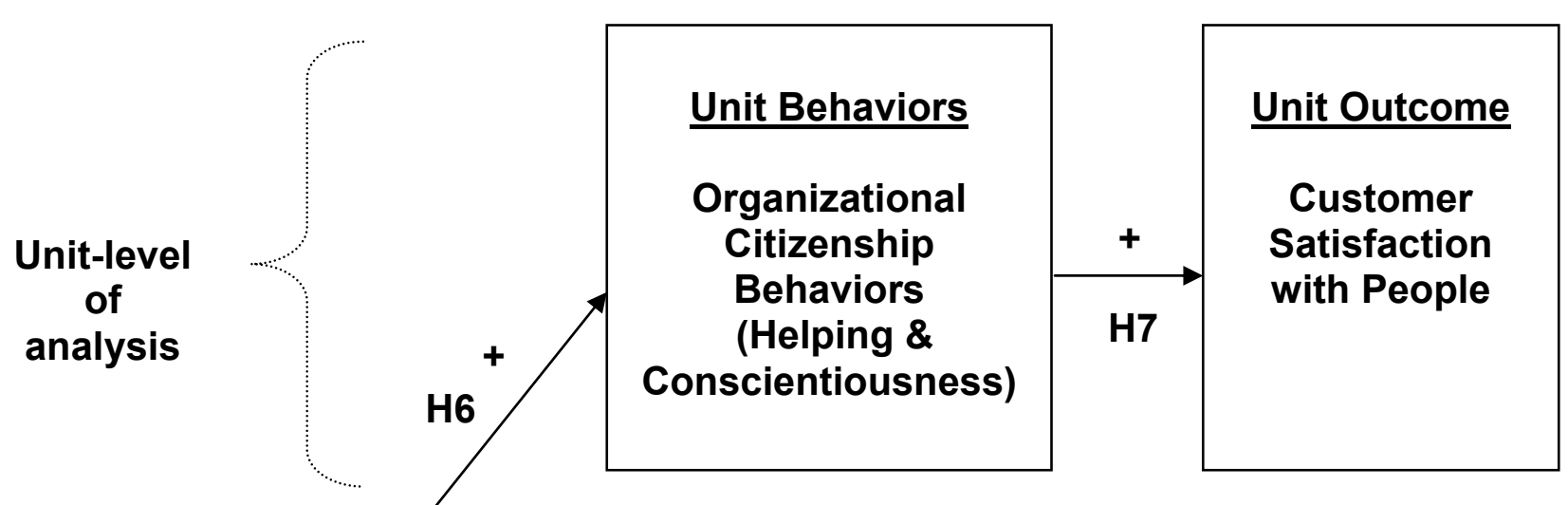

\section{Attributions regarding} business goal underlying HR

Service Quality (H1)

Cost Reduction (H2)

Attributions regarding

HR philosophy

Employee well-being $(\mathrm{H} 3)$

Exploiting Employees

(H4)

External Attribution

Compliance with union

contract (H5)

\section{Attitudes}

Affective

Commitment

$\&$

Satisfaction 


\section{METHODOLOGY}

\section{Participants and Procedure}

The criteria according to which we selected an organization to participate in this research was that the organization be structured around meaningful units and units with common indices of performance in order to enable tests of the hypotheses at the unit level. An additional criterion was that data from multiple sources would be available in order to reduce single source bias. Our aim was to collect HR Attributions, commitment, and satisfaction data from employees within departments, OCB data from the manager of each department, and customer satisfaction data from the customers of each department.

The organization that matched these criteria was a supermarket chain with stores that each contains approximately 18 departments. For each of these departments, customer satisfaction data were available and used as the performance measure. The uniformity of HR practices across the organization, and in particular across the 18 different types of departments, was confirmed through discussions with the head of HR for the company. A single document detailing the organization's HR policies and practices is considered to be applicable to all employees, and the presence of a union in the supermarket chain further enhances the likelihood that common rules and guidelines are familiar to all across the units.

After study measures were finalized with focus groups to ensure understandability and relevance with regard to language, participants voluntarily completed the surveys during work hours. In order to assure respondents of the confidentiality of their responses, all completed surveys were sent directly to the researchers rather than to corporate headquarters.

Respondents indicated the department within the store in which they worked. Data were collected from 4,500 employees and 1,100 department managers. Of the employees, $37 \%$ were male, $81 \%$ were Caucasian, $38 \%$ were above the age of 40 , and $65 \%$ had been at the company for fewer than 5 years. Of the department managers, $48 \%$ were male, $94 \%$ were Caucasian, and $60 \%$ had been at the company for fewer than 5 years. Over $90 \%$ of the respondents were from unionized stores, thereby making comparisons based on unionization 
impossible; therefore, only unionized stores were included in the analyses. The final sample included 4208 employees and 1010 department managers, nested within 362 departments across 95 stores $^{1}$.

\section{Measures}

HR Attributions. As a first step toward developing a measure of HR Attributions, we first informally surveyed 25 organizational scholars asking them to brainstorm on the different possible attributions that employees might make for HR practices. We asked that they base their responses on their own experiences and the experiences of others, as well as on what they know of the research literature. There was considerable overlap across respondents, and the responses that we received could be categorized into themes that were closely aligned with the typology of 5 HR Attributions that we developed based on the literature. Thus, we felt confident about proceeding to test our typology of HR attributions. In order to do so, we developed measures of the five proposed HR attributions, as there are no existing measures of HR Attributions. An item representing each of the five proposed HR Attributions of theoretical interest was included for each of 5 main HR practice areas: staffing, training, benefits, pay, and performance appraisals. That is, for each HR practice respondents were asked to indicate the degree to which the HR practice was designed in order to 1) enhance (service) quality; 2) keep costs down; 3) promote employee well-being; 4) get the most work out of employees; and 5) comply with union requirements. We also included an item each for the two HR attribution categories that emerged from our informal poll of organizational scholars but which we had not originally included in our typology: the extent to which each HR practice was designed in order to 6) keep up with what other companies are doing, and 7) to produce a positive image in the marketplace and earn the company a reputation for being a leader in the industry.

In a first round of 5 focus groups in which we piloted our measure, employees and department managers were asked to provide feedback on the content and wording of the HR Attribution items. Specifically, they were asked to comment on items that were unclear or that were not directly relevant to the organization, and were also asked to indicate whether there 
might be other HR attributions worth including in our survey. Their feedback centered around 3 main issues. First, with regard to the content of the HR attributions, they did not identify other HR attributions that they thought we should include in our survey. However, the majority of focus group participants told us that they do not know what other companies (particularly not competing supermarket chains) are doing with respect to the HR practices about which we inquired, and thus they suggested that it would be less confusing to survey participants if we excluded the attributions relating to institutional pressures (HR attribution 6 , above) and public reputation (attribution 7, above), both which require some understanding of HR trends in the marketplace. Second, focus group participants struggled with the wording of the item we had written to represent the Exploiting Employees HR Attribution. Consistent with conceptualizations of employee-oriented philosophies (Lepak, et al., 2002), we originally asked employees about the extent to which HR practices were designed to control, monitor, and/or direct employee behavior. However, based on their input, the item was reworded to ask about the extent to which employees perceived that HR practices were designed to "get the most work out of employees." Finally, in regard to the HR practices about which we inquired, focus group participants explained that due to the heavy union presence, employees do not undergo formal performance appraisals, and thus explained that this was not an appropriate HR practices on which to focus. Instead, employees described scheduling (i.e., number of hours per employee, number of employees per shift) as being an important HR practice with consequences for employee attitudes and behavior. Therefore, scheduling was included in place of performance appraisals as one of the 5 HR practices.

In a second round of 5 focus groups, we piloted our revised measure of HR attributions. We presented an item representing each of the $5 \mathrm{HR}$ Attributions we originally proposed, and asked respondents to evaluate each of $5 \mathrm{HR}$ practices—staffing, training, benefits, pay, and scheduling - with regard to the extent to which they perceived each of the $5 \mathrm{HR}$ Attributions as being relevant. Thus, respondents answered a total of 25 questions: $5 \mathrm{HR}$ attribution questions for each of $5 \mathrm{HR}$ practices. As can be seen in Appendix 1, the HR Attribution items were 
organized by HR practice and not by HR Attribution (i.e., 5 attributions were listed for each of 5 HR practices. We did not receive any comments to suggest that further revisions to our measures were necessary, thus we collected data using these 25 items. Each of the items was rated on a 5-point Likert scale ranging from $1=$ not at all, to $5=$ to a great extent, indicating the extent to which the respondents perceived each of the HR Attributions to be relevant for the HR practices.

We conducted a confirmatory factor analysis (CFA) to examine how well the data fit the proposed 5 factor structure of HR Attributions. Specifically, the 5 items (1 for each HR practice) referencing the service quality attribution were loaded onto a single factor, the 5 items referencing the cost reduction attribution were loaded onto a single factor, and so on. Results indicated relatively poor fit $\left(\mathrm{X}^{2}{ }_{(233)}=6394.17 ; \mathrm{CFI}=.82 ; \mathrm{RSMEA}=.09 ; \mathrm{SRMR}=.07\right)$, and the modification indices suggested that a primary reason for poor fit was that the Service Quality and Employee Well-being factors were highly correlated, and thus we ran a subsequent model in which the HR Attribution items were loaded onto 4 factors: a combined Service Quality and Employee Well-being factor, and the proposed Cost Reduction, Exploiting Employees, and Union Compliance factors. The fit for this model was acceptable $\left(X^{2}{ }_{(213)}=3708.27 ; C F I=.90\right.$; RSMEA=.07; SRMR=.06), and was significantly better $\left(x_{(1)}^{2}=2685.9 ; p<.01\right)$ than for the 5 -factor model.

Although Service Quality and Employee Well-being were hypothesized to comprise separate factors, it is not altogether surprising that the results of the CFA suggested that they should be combined, for service researchers maintain that in order for service employees to deliver quality service, they must feel that they are treated well by their companies (Morrision, 1997; Schneider \& Bowen, 1995). Thus, HR practices that signal the importance of service quality should also signal the importance of employee well-being in order to be maximally effective; from the employees' perspective, then, if they perceive that the underlying managerial goals of HR practices is to "help employees deliver quality service," then they apparently also perceive that HR practices are designed with the goal of maximizing employee well-being. 
Moreover, it is likely that these two sets of items factored together because of their shared concern for people: a concern for employees and for customers. Indeed, we had grouped these two HR attributions together conceptually in Table 1 based on their shared "commitmentenhancing" focus. Thus, we labeled this combined HR attribution "Quality and employee enhancement HR Attribution." Cronbach's alpha for this factor was $\alpha=.91$.

In order to recognize the possibility that the Cost Reduction and Exploiting Employees HR attributions might also similarly be combined to reflect their shared "control" focus, we also tested a 3 factor attributions model containing a concern for people factor (Service quality and employee well-being HR attributions combined), control-focused factor (Cost reduction and Exploiting Employees HR attributions combined), and neutral, external attribution factor (Union compliance HR attribution). We found that the fit was good $\left(X_{(194)}^{2}=2439.03 ; C F I=.91\right.$; RMSEA=.06; SRMR=.06), and was significantly better $\left(X^{2} \Delta_{(17)}=404.63\right)$ than the 4 factor model just reported. In recognition of these results, we combined the Cost Reduction and Exploiting Employees HR attributions into a single factor named "Cost and employee exploitation HR Attribution." Cronbach's alpha for this factor was $\alpha=.82$, and for the Union Compliance scale it was $\alpha=.79$.

Affective commitment and satisfaction. At the individual level of analysis, Affective commitment was measured using 4 items adapted from the well-established scale by Meyer, Allen, and Smith (1993). An example item is, "I feel a strong sense of 'belonging' to [company name]." Cronbach's alpha was $\alpha=.92$. As for employee satisfaction, of interest in this study was employees' satisfaction with their overall position as an employee of a company. Some authors have argued in favor of global measures over sums of facet satisfaction measures (e.g., Ironson, Smith, Brannick, Gibson, \& Paul, 1989), and therefore we measured satisfaction using an adapted version of the gender-neutral single-item Faces Scale (Dunham \& Herman, 1975). Contrary to popular thought in our field, that single-item measures are undesirable due to poor reliability, Wanous, Reichers, and Hudy (1997) conducted a meta-analysis in which they utilized 
the correction for attenuation formula to conclude that, at a minimum, the estimated reliability for single-item measures of satisfaction is close to .70 .

Preliminary analyses suggested that commitment and satisfaction were highly correlated $(\underline{r}=.50 ; p<.01)$, and thus we conducted a CFA at the individual-level of analysis to see whether a model in which the two attitude variables were combined was superior to one in which they were not. Assuming a 3 factor solution for the HR attribution items, as described above, we compared a 4 factor model (in which satisfaction and commitment are combined) to a 5 factor model (in which satisfaction and commitment are kept separate) and found the more parsimonious 4 factor solution $\left(X^{2}{ }_{(316)}=2930.26\right.$; $C F I=.92 ; R_{M S E A}=.05 ;$ SRMR=.06) was a significantly better fitting model $\left(X^{2} \Delta_{(1)}=793.94\right)$ than the 5 factor model $\left(X_{(317)}^{2}=3724.20\right.$; $\mathrm{CFI}=.90$; RMSEA=.06; SRMR=.08). An exploratory factor analysis confirmed this result, as a single employee attitudes factor representing the 4 affective commitment items and 1 global satisfaction item emerged and explained $71 \%$ of the variance. Thus, for simplicity's sake, we proceeded to test study hypotheses using this combined Employee Attitudes factor rather than treating commitment and satisfaction separately. The reliability for this combined scale was $\alpha=$ .90 .

Group-level employee attitudes were expected to follow the fuzzy composition (Kozlowski \& Klein, 2000) or referent-shift (Chan, 1998) model of composition/aggregation, according to which the group-level construct is expected to differ in subtle ways from the individual-level construct due to the influence of higher-level contextual influences that are not captured by the lower-level construct (e.g. shared contextual features, group tasks, group leadership, etc.; Bliese, 2000). In order to justify the aggregation of the employee attitudes scale (combined employee commitment and satisfaction) to the unit-level of analysis, we calculated ICC-(1) and ICC-(2) values (Bartko, 1976; James, 1982) as well as the $r_{\mathrm{wg}}$ statistic using a uniform distribution as the null distribution (James, Demaree, \& Wolf, 1984). The ICC(1) was .06, the ICC-(2) was .36, and the mean $r_{w g}$ was $.77^{2}$. The ICC-(1) and rwg values were within the recommended range of .05-.20 (Bliese, 2000) and above .60 (James, 1982), 
respectively. The ICC-(2) value, which assesses the reliability of the group means, was lower than the recommended .60 cutoff (Glick, 1985). However, the $F$ test for employee attitudes was significant $\left(F_{(361,2873)}=1.55 ; \underline{p}<.01\right)$, and we used this as another index for justifying the appropriateness of aggregation (Bliese, 2000).

Although the ICC-(2) statistic was lower than the recommended cutoff, it is important to put this into perspective. In particular, the attitudes were assessed with the individual, and not the group, as the referent, since the constructs originate in the psychological processes of individuals. Thus these aggregation statistics relate to sharedness of personal attitudes, not about perceptions about an external group-level construct, the latter which is the usual focus for aggregation statistics. Thus, recall the examples of satisfaction and commitment items noted earlier. Each of those has the individual respondent as the frame of reference rather than the department so we are, indeed, aggregating personal internal reflections and not observations of the shared external world.

It is worth noting that we attempted to reduce the possibility of common method bias involving employee attitude data (i.e., HR attributions, satisfaction, and commitment) using recommended proximal and methodological separation techniques (Podsakoff et al., 2003). First, the measurement of HR attributions and employee attitudes appeared in separate sections of our survey, and were separated by different sets of instructions and by the measurement of a construct not included in this study. In addition, we separated HR attributions and employee attitudes methodologically by assessing employee satisfaction using a different scale format than that used for HR attributions and commitment. Whereas the HR attribution and commitment items utilized a 5 point Likert-type scale, satisfaction was assessed using a faces scale.

Organizational citizenship behaviors. Group-level constructs that are observable and are clearly group-level phenomena are good candidates to be measured with the group as the referent. Therefore we measured a two-dimensional categorization of OCBs consistent with Organ's (1997) recommendation, which includes the helping and conscientiousness 
dimensions. We did so using Podsakoff and colleagues' items (Podsakoff, MacKenzie, Moorman, \& Fetter, 1990) re-worded with the department as the referent. The Helping dimension involves giving assistance to fellow co-workers. An example item is, "In my department, employees are always ready to lend a helping hand to other employees around them." Cronbach's alpha was $\alpha=.89$. The Conscientiousness dimension includes behaviors such as attendance and following rules. An example item is, "In my department, employees obey rules and regulations even when no one is watching." Cronbach's alpha was $\alpha=.85$. Because the two OCB dimensions were assessed at the unit level by a single rater (department managers), aggregation to the unit level was not necessary, and therefore neither are aggregation statistics.

Customer satisfaction. To assess customer satisfaction, we utilized the 11 items used by the participating organization. Department employees were rated by customers, for example, on friendliness and knowledge, and products were rated on freshness and availability. When the items were submitted to an exploratory factor analysis, four dimensions emerged: Satisfaction with people $(\alpha=.93)$, product $(\alpha=.95)$, place $(\alpha=.88)$, and price (measured by a single item). The facet of customer satisfaction that is most relevant in the current study-and was therefore used in all analyses-is Customer Satisfaction with People, as employee attitudes and behaviors are not likely to influence the satisfaction that customers experience with price, product or place. As these data were provided to us already aggregated to the department level of analysis we do not have aggregation statistics available for them.

\section{Analyses}

In order to test the hypotheses, we conducted two latent variable structural equation models, one at the individual-level of analysis to test hypotheses 1-5, and another at the department level to test hypotheses 6 and 7 . In the individual-level structural equation model used to examine the relationships between the HR Attribution scales and employee commitment and satisfaction, the non-independence of observations due to cluster sampling (within departments) was taken into account when computing standard errors and chi-square tests of 
model fit ${ }^{3}$. By doing so, we were able to avoid violating non-independence statistical assumptions, as is often the case when nested organizational data is examined without taking non-independence of observations into account (Hoffman, 2000). In both the individual-level and unit-level models, the indicators of the continuous latent variables were included in the model, and the MPlus software was used to analyze the data. Analyses were conducted only on departments with at least 4 respondents, in order to minimize instability in the data.

In addition, because it is not possible to collect employee attitude data from multiple sources, we attempted to address common method bias in the employee attitude data by conducting the Harman's one-factor test, which is the most commonly used technique for addressing common method variance (Podsakoff, et al., 2003). We compared the one-factor Harman's CFA solution to a four-factor solution for employee attitudes (3 factors for HR attributions and a combined attitudes factor) and found that the single-factor solution does not fit the data $\left(\mathrm{X}^{2}{ }_{(323)}=7179.51 ; \mathrm{CFI}=.80\right.$; $\left.\mathrm{RMSEA}=.09 \mathrm{SRMR}=.12\right)$, and is indeed significantly worse $\left(X^{2} \Delta_{(7)}=4249.25\right)$ than the four-factor solution $\left(X_{(316)}^{2}=2930.26\right.$; CFI=.92; RMSEA=.06; SRMR=.06). Thus, we conclude that there is at least some evidence that a single methoddriven factor does not adequately represent our data.

\section{RESULTS}

\section{Descriptive Statistics}

Means and standard deviations for the individual-level variables are displayed in Table 2 , as well as correlations among the variables. Because the responses from employees within a department are likely to share some variance (or be characterized by "non-independence") as a function of shared experiences, we present partial correlations that control for department. In Table 3, we present the means and standard deviations for the department-level variables, as well as the correlations among them. The correlations were conducted on data from departments with at least 4 respondents, which yielded a total of 362 departments, although department manager and customer satisfaction data were not available for all of those departments, thereby further reducing the sample size in some analyses. 
Table 2

Partial correlations among individual-level variables, controlling for department

\begin{tabular}{|l|c|c|c|c|c|c|}
\hline Scale & Mean & S.D. & $\mathbf{1}$ & $\mathbf{2}$ & $\mathbf{3}$ & $\mathbf{4}$ \\
\hline $\begin{array}{l}\text { 1. Quality \& employee enhancement } \\
\text { HR Attribution }\end{array}$ & 3.01 & .89 & & & & \\
\hline $\begin{array}{l}\text { 2. } \\
\text { Cost \& employee exploitation HR } \\
\text { Attribution }\end{array}$ & 3.27 & .77 & $.38^{* *}$ & & & \\
\hline 3. Union Compliance HR Attribution & 3.37 & .87 & $.17^{* *}$ & $.56^{* *}$ & & \\
\hline 4. Affective Commitment & 2.79 & 1.14 & $.61^{* *}$ & $.25^{* *}$ & $.09^{* *}$ & \\
\hline 5. Satisfaction & 3.45 & 1.03 & $.44^{* *}$ & $.08^{* *}$ & .01 & $.50^{* *}$ \\
\hline 6. Combined Employee Attitudes & 2.93 & 1.03 & $.63^{* *}$ & $.24^{* *}$ & $.08^{* *}$ & -- \\
\hline
\end{tabular}

** $\underline{\mathrm{p}}<.01$

$\underline{N}=3188-3242$ individuals, depending on the number of missing values for each correlation.

Table 3

Correlations among unit-level variables

\begin{tabular}{|c|c|c|c|c|c|}
\hline Scale & Mean & S.D. & 1 & 2 & 3 \\
\hline $\begin{array}{l}\text { 1. Employee Attitudes } \\
\text { (commitment \& satisfaction } \\
\text { combined) }\end{array}$ & 2.93 & .47 & & & \\
\hline 2. OCB-Helping dimension & 3.89 & .80 & $\begin{array}{c}.13 \dagger \\
(n=185)\end{array}$ & & \\
\hline $\begin{array}{l}\text { 3. OCB-Conscientiousness } \\
\text { dimension }\end{array}$ & 4.03 & .71 & $\begin{array}{c}.16^{*} \\
(\mathrm{n}=185)\end{array}$ & $\begin{array}{c}.66^{* *} \\
(n=185)\end{array}$ & \\
\hline $\begin{array}{l}\text { 4. Customer satisfaction with } \\
\text { people }\end{array}$ & 3.51 & .24 & $\begin{array}{c}.09 \\
(n=109) \\
\end{array}$ & $\begin{array}{c}.28^{* *} \\
(\mathrm{n}=109)\end{array}$ & $\begin{array}{c}.11 \\
(n=109) \\
\end{array}$ \\
\hline
\end{tabular}

\section{Test of study hypotheses}

Due to the fact that the Service Quality (hypothesis 1) and Employee Well-being (hypothesis 3) HR Attributions were combined to create a single Enhancing quality and employee HR Attribution, and the Cost Reduction (hypothesis 2) and Exploiting Employees (hypothesis 4) HR Attributions were combined into a single Exploiting costs and employees HR Attribution, tests of hypotheses 1 and 3, and hypotheses 2 and 4, respectively, were combined. An individual-level structural equation model designed to test these hypotheses exhibited good fit $\left(X_{(313)}^{2}=2866.61 ; \mathrm{CFI}=.93\right.$; RMSEA=.05; SRMR=.06), and provided support for our 
hypotheses. Consistent with the directionality of hypotheses 1 and 3, the Enhancing quality and employee HR Attribution was positively associated with employee attitudes $(\beta=.70 ; \underline{p} \leq .01)$, and the Exploiting costs and employees HR Attribution was negatively associated with attitudes $(\beta=-.06 ; \underline{p} \leq .05)$. Union Compliance HR Attribution was unrelated to attitudes $(\beta=-.04 ; \underline{p} \geq .05)$. Significant paths are depicted with solid arrows, while non-significant ones appear as dashed arrows in Figure 2.

Figure 2:

Hypotheses $1-5$ at the individual-level of analysis $\left(X^{2}{ }_{(313)}=2866.61 ; C F I=.93 ;\right.$ RMSEA=.05; SRMR=.06)

HR Attributions

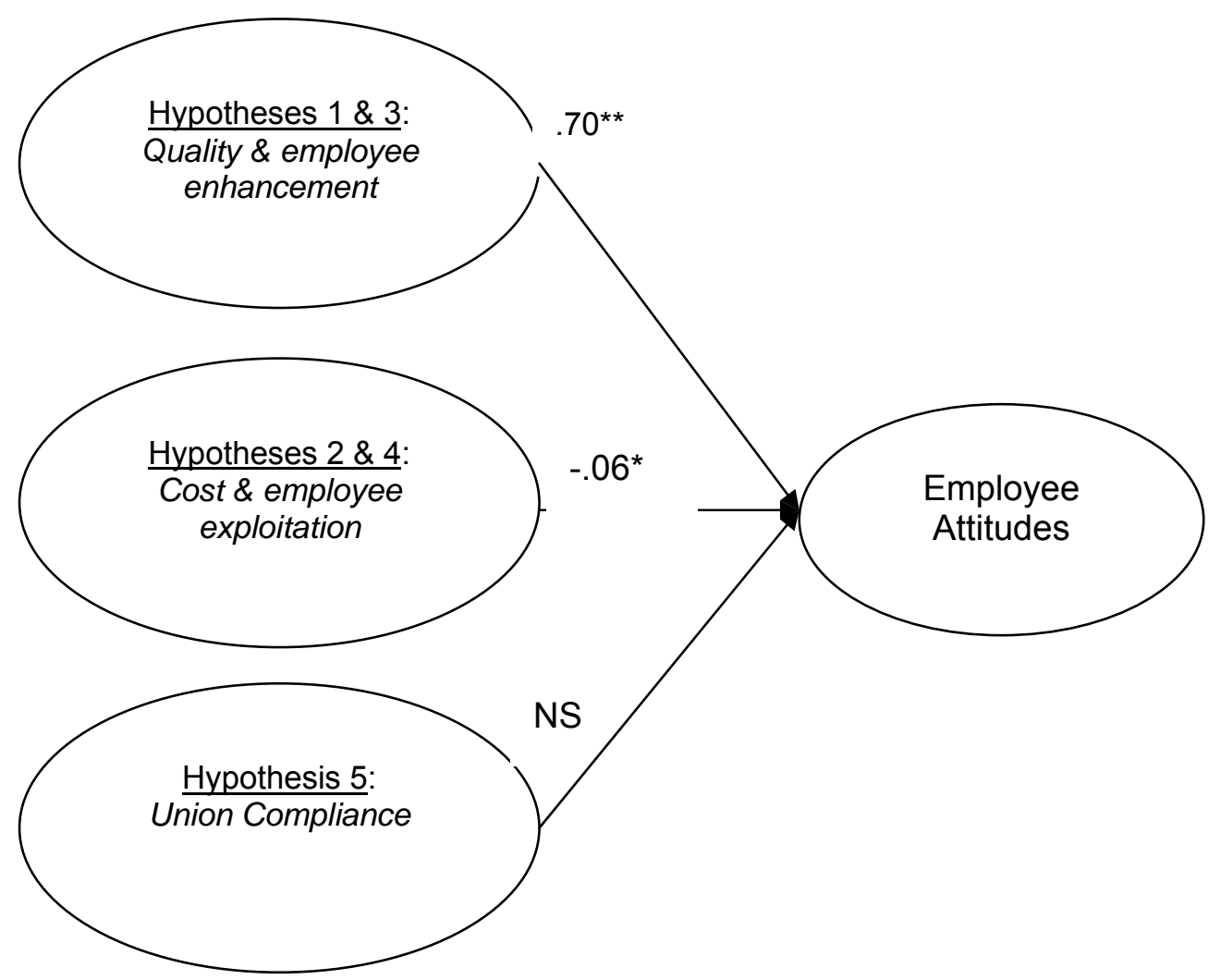


Figure 3:

Hypotheses 6-7 at the unit-level of analysis $\left(x_{(94)}^{2}=85.54 ; C F I=1.00 ;\right.$ RMSEA=.00; SRMR=.05)
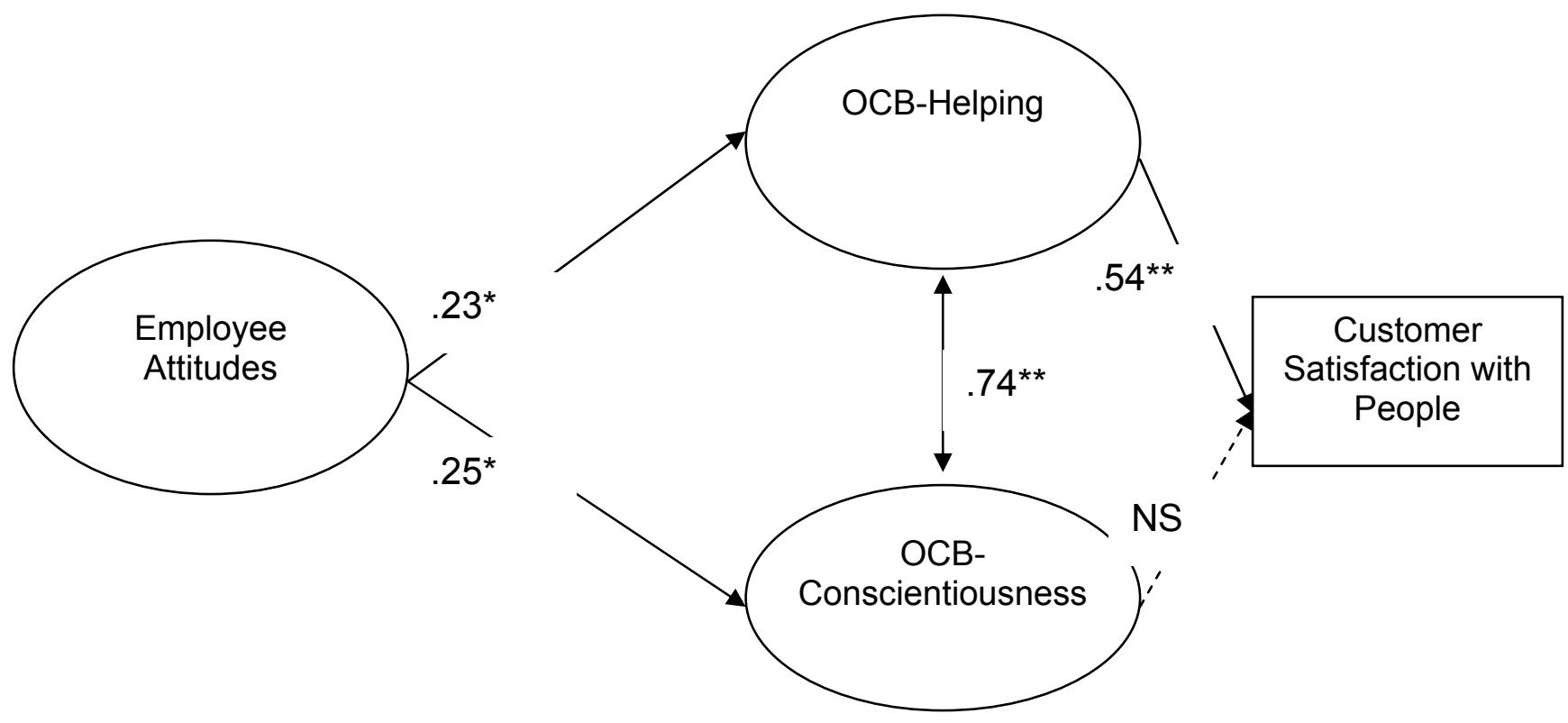

Prior to running analyses to test the department-level model, the variables were standardized by department type in order to rule out the possibility that observed results may be a function of between-department differences in the salience of the HR practices to the departments, to satisfaction or commitment, and so forth. Thus, all reported results are based on z-scores. The model shown in Figure 3 fit the data extremely well $\left(X^{2}{ }_{(94)}=85.54 ; C F I=1.00\right.$; RMSEA=.00; SRMR=.05). The path coefficients shown in Figure 3 support hypothesis 6 , indicating that employee attitudes are positively associated with unit-level OCBs. Employee attitudes was significantly associated with both OCB-Helping $(\beta=.23 ; \underline{p} \leq .05)$ as well as OCBConscientiousness $(\beta=.25 ; \underline{p} \leq .05)$. In partial support of hypothesis 7 , we found that OCBHelping was significantly associated with customer satisfaction $(\beta=.54 ; \underline{p} \leq .01)$ but OCBConscientiousness was not $(\beta=-.28 ; p \geq .05)$. 


\section{DISCUSSION}

Overall, our results supported the notion that employees make attributions about the purpose(s) for the HR practices in their organization, and that these HR Attributions are differentially associated with attitudes. As expected, the attribution that HR practices are motivated by the organization's concern for enhancing service quality and employee well-being was positively related to employee attitudes, the attribution focused on reducing costs and exploiting employees was negatively associated with attitudes, and the external attribution involving union compliance was not significantly associated with attitudes. In turn, unit-level attitudes were significantly associated with the two dimensions of OCBs, and OCB-Helping was significantly related to customer satisfaction. We believe that these findings have important theoretical, methodological, and practical implications.

These results support the idea that there are likely cross-level and emergent processes in organizations through which HR practices are associated with individual-level responses to those HR practices, which in turn emerge in conceptually meaningful ways at higher levels of analysis to be linked with group level performance. Most importantly, the results suggest that the same set of HR practices may not even exhibit similar effects within a single organization. The implication is that it's not just the HR practices themselves, but rather also employees' perceptions of those HR practices that are important for achieving desired organizational outcomes.

\section{Theoretical Implications and Directions for Future Research}

Our findings contribute to SHRM research and theory in a number of important ways. First, although a number of scholars have suggested that employees' interpretations or attributions of HR practices are likely to play an important role in influencing the ultimate effect of HR practices, our study is among the first to provide evidence that this is the case. Our research confirms the argument made by Nishii and Wright (in press; Wright \& Nishii, in press) that meaningful variability exists within organizations - in terms of employees' perceptions of and reactions to HR practices - and that implicitly ignoring this variability by focusing on single 
organizational respondents' reports of HR practices in their organizations may be hurting our ability to understand the process through which HR practices become linked to performance. Our research suggest the utility of focusing more future SHRM research on the way that HR practices are enacted in organizations, as revealed in human perception and behavior, in addition to a focus on HR content and policy development (Purcell, 2005).

A second, related point is that researchers should take caution in relying on managers' reports of HR practices. As Wright and Nishii (in press) suggested, there is likely to be a disconnect between intended HR practices as reported by managers and the effect of actual HR practices that is at least partially explained by differential meanings imposed on those practices by employees. Because managerial and employee reports of HR practices may differ in important ways, future researchers should explicitly recognize this distinction and acknowledge whether their focus is on intended versus actual and perceived HR practices, and the implications for SHRM theory therein.

Third, we believe that our findings may be informative for trying to disentangle some of the inconsistent findings to date regarding external fit. Specifically, equivocal findings about the benefits of aligning HR practices to business strategy may be explained in part by the commonly adopted methodology in which single respondents are asked to report on a firm's HRM system and strategies. Such a methodology does not permit the researcher to examine employees' attributions regarding the strategic goals underlying HR practices; yet, the degree to which employees understand the strategic goals underlying HR practices may impact the effectiveness of those HR practices (cf. Wright \& Boswell, 2002). For example, when comparing two organizations with the same business strategy and set of HR practices, the relationship between HR practices and performance could be stronger in the organization in which employees' attributions regarding the strategic goals underlying the HR practices are more closely aligned with the organization's intended strategy.

Fourth, the construct of HR Attributions may also be useful when thinking about internal fit or alignment among HR practices. Given that a primary objective of internally aligning HR 
practices is to send consistent messages to employees regarding the firm's goals and expectations for employee behavior, it may be more appropriate to explore notions of internal fit from the employees' perspective rather than rely on HR representatives' assumptions or researchers' calculations of internal fit. Indeed, it is reasonable to expect that in some cases, even if a firm's HR practices appear to be internally consistent on paper, they may not be experienced as such by employees. From the employees' perspective, alignment HR practices would be evidenced by coherence or consistency in the HRM-related messages that employees receive from the HR practices to which they are subject, as well as agreement across employees. More specifically, in an organization in which HR practices are internally aligned, one might expect employees' attributions about HR practices to be rather uniform across the specific HR practices about which employees are asked to respond (e.g., training, staffing, pay, benefits, and scheduling, among others). In addition, there should be relatively little variability across employees and units regarding the attributions that are made for the firm's HR practices. This was not the case for employees in the organization participating in our research. Future research that explores the potential moderating role of consistency in HR Attribution perceptions - both within individuals across HR practices, and across individuals within organizations - on the relationship between HR practices and performance would help to she light on some of these issues.

Our research findings are suggestive of several additional avenues for future research. First, our data show that people's attributions for the same HR practices differ, and that these differential attributions have implications for valued outcomes, and thus future research that examines the antecedents of people's attributions is necessary. Given that the way that objects are perceived by individuals depends on attributes of the object itself, the context within which it is perceived, and the characteristics of the perceiver (Brunswik, 1956), research should focus on identifying the attributes of HR practices that are particularly salient or informative as far as attributions are concerned (e.g., is it the design of HR practices, the message that they tell relative to other communications from management, or the fairness with which they are 
implemented within the organization?), other contextual cues that are particularly influential in the attribution process (Bruner, 1957; Kelley \& Michela, 1980), and the individual difference factors that contribute to variability in people's HR attributions (Golding \& Rorer, 1972). Indeed, it is possible that people's HR attributions are influenced as much by individual difference factors (e.g., personality, values, goals, needs, social roles, past experiences, competencies, expectancies) as by organizational practice, as people's attributions will be based on how they selectively attend to information regarding HR practices as well as how they process that information; specifically, differences in the criteria according to which HR practices are judged (Mischel \& Shoda, 1995). Although we interpreted the factor structure of internal HR attributions to represent a "quality and employee enhancement HR attribution" and a "cost and employee exploitation HR attribution," we cannot rule out the possibility that the positive and negative HR attribution factors, respectively, may be driven by positive and negative affectivity on the part of respondents ${ }^{4}$. Thus, future research that teases apart the relative contributions of individual and organizational factors that influence employees' HR attributions would be valuable.

As our discussion of the individual-level antecedents of HR attributions suggest, we conceptualized HR attributions as an individual-level phenomenon in this study. Indeed, aggregation statistics confirmed that HR attributions were not sufficiently shared among department members so as to represent a meaningful unit-level construct. However, it is entirely possible for HR Attributions to emerge as a group-level construct in other organizational contexts. The extent to which group members come to share their HR attributions is likely a function of the quantity and quality of social interaction patterns within the group that affect the extent of group sensemaking that takes place (Weick, 1995). These social interaction patterns may be influenced by the level of task interdependence, interpersonal liking, and group diversity within a group, as well as the degree of shared context, leadership, roles, norms, or task goals (James, Joyce \& Slocum, 1998; Kozlowski \& Hattrup, 1992). When group members engage in extensive social interactions and collectively make sense of their organizational environments, they are likely to share organizational assumptions and mutually influence the way that they 
perceive HR practices. Thus, while we theorize HR attributions as originating in the psychological processes of individuals, group conditions may lead some groups to coalesce more than other groups in their perceptions of HR Attributions. Future research that further explores the emergence of HR attributions as a group-level construct would be informative.

Bowen and Ostroff (2004)'s model of the features of HR systems that influence employees' perceptions of HR practices is untested, and thus future research is needed to examine whether their model may be useful for understanding the antecedents of employees' attributions regarding the why of HR practices. We expect some aspects of their model to be informative for understanding the antecedents of HR attributions. For example, we expect that variability across employees' HR attributions should be reduced when communication regarding $\mathrm{HR}$ is unambiguous. As might be expected based on social psychological theories of attitude formation and change (Eagly \& Chaiken, 1993), we expect HR attributions to be shaped by the volume, presentation, and timing of discrepant information regarding HR practices, such that HR attributions should be most widely shared when thorough and unambiguous information is presented to employees early in their tenure at an organization when they are especially motivated to attend to information about organizational practices. Furthermore, we expect that such HR information will be more influential in the formation of employees' HR attributions when the source of that information is credible (e.g., when the HR function is seen as a legitimate authority, Bowen \& Ostroff, 2004). When organizational communicators are not seen as credible, then employees may be more likely to rely on their own subjective perceptions as well as those of their coworkers when interpreting HR practices. Although early attribution theory assumed that the social perceiver engaged in attributional processes alone, later theorists recognized the likelihood that social perceivers turn to others for explanations when trying to determine the cause of a behavior or event (e.g., Antaki, 1985). When employees engage in collective sensemaking they will come to share their HR attributions. Future research, preferably utilizing data collected from multiple organizations to take advantage of between- 
organization variability, should explore the processes through which employees share HR attributions, and the effects associated with weakly versus strongly shared attributions.

It is also reasonable to expect that when faced with attributional uncertainty, employees might turn to their more knowledgeable managers for explanations about the HR practices. Thus, future research that examines the influence of managers' HR attributions on the attributions of their employees, as well as the interaction of the two, would be valuable. An interesting possibility is that due to the actor-observer effect, which is the tendency to attribute others' behavior to dispositional factors but one's own behavior to situational ones (Jones \& Nisbett, 1972), managers and employees may be predisposed to make differing attributions regarding HR practices. This of course assumes that employees perceive managers as implementers of HR practices, which some research suggests they do (Zohar, 2000; Zohar \& Luria, 2004). When managers are perceived as the actor, or as the implementer of HR practices, then employees are likely to attribute dispositional factors as underlying the design and implementation of HR practices (e.g., manager is fair, caring, etc.) and may be unable to see other possible explanations for HR practices. However, other, situational explanations may exist for HR practices, explanations which are perceptible to managers and HR professionals. Such divergence in attributions between managers and their subordinates may be problematic, as discrepant attributions have been associated with greater subordinate dissatisfaction (Wexley, Alexander, Greenawalt, \& Couch, 1980) and may also be related to greater conflict between managers and subordinates (Martinko \& Gardner, 1987). Thus, future research would benefit from examining whether such actor-observer differences in HR attributions exist, and if they do, examine how they interact in affecting employee attitudes and behavior. Such differences may partially account for varying reports of HR practices as perceived by HR professionals, managers, and employees. Nevertheless, because individuals act based on their own perceptions, assessing employees' HR attributions is critical.

It would also be valuable to examine the conditions under which employees are motivated to seek information about the underlying goals of management that drive HR 
practices. Bowen and Ostroff (2004) suggest that this is most likely when employees perceive that they are dependent on HR practices for attaining their personal goals. We expect employees to always perceive HR practices as being relevant for them, but it may be that employees' greater ongoing dependency on some practices (e.g. pay, benefits, scheduling) than others (e.g., selection) may make them more likely to attend to information surrounding those HR practices than others when making their HR attributions. In addition, it is possible that people may be cognitively predisposed to make internal HR attributions much more often than external HR attributions. This tendency, referred to as the fundamental attribution error (Ross, 1977), is well documented. One explanation for this bias is that dispositional attributions occur rather spontaneously, while collecting situational information that might provide alternative explanations for behavior/events is often more cognitively taxing (Gilbert, Pelham, \& Krull, 1988). This is consistent with what we learned in our focus groups, in which employees told us that they would have a hard time considering the attribution that HR practices were designed in response to institutional pressures (i.e., management adopts the HR practices that it does to be consistent with peer companies), since they know little about the HR practices employed by peer companies. Thus, when important situational factors are at play, extra communication efforts may be required to make them salient to employees. It is, however, possible that in other organizations - such as those that are known for their HR practices or which are dominated by knowledge workers - employees may be more familiar with institutional norms surrounding HR practices, and that therefore external attributions related to institutional pressures would be more prevalent. Research aimed at understanding these nuances, and their implications for organizational communication efforts, would be beneficial.

Finally, future research should consider cross-cultural extensions of our theory. For example, research (e.g., Fletcher \& Ward, 1988) has shown that the fundamental attribution error is much less common in collectivistic cultures such as Japan, perhaps suggesting that external HR attributions may be more common in those cultures. If this were the case, it may be that HR attributions may play a smaller role in impacting employee attitudes and behaviors in 
collectivistic than individualistic cultures. Or, it could also be the case that in collectivistic cultures, in which responding to situational demands is paramount, external attributions that reflect such pressures will be more influential for employee attitudes and behaviors. This, as well as other cross-cultural extensions of our theory, would be worthwhile to explore.

\section{Practical Implications}

The goal of HRM is to design and implement HR practices in a way that leads to desired employee attitudes and performance. The question that should be of interest to HR practitioners, therefore, is whether a firm's HR practices are successfully accomplishing these goals as intended, and if not, to identify the factors that might be responsible. By testing a cross-level model that linked employees' subjective attributions of HR practices to their attitudes and behaviors, and ultimately to customer satisfaction, we showed that employees' HR attributions may at least partially account for the varied success with which HR practices ultimately impact organizational performance. For HR practitioners, this suggests that assessing HR attributions can provide valuable information about why HR practices have or have not accomplished organizational goals as intended. Rather than focusing solely on managerial assessments of fit among HR practices, our results suggest the benefits of shifting attention to employee assessments of fit. Doing so may help illuminate problematic areas that are not viewed as problematic by managers but are perceived as so by employees. By closely examining employees' HR attributions practitioners can get a sense for whether some HR practices, but not others, may be to blame. In doing so, it would be important to examine not only the mean HR attributions made, but also the variance in those attributions. For a particular HR attribution desired by management, it may be that there is great variability across HR practices in the extent to which employees perceive that attribution to be relevant, or it could be that there is great variability across employees in the extent to which they perceive the attribution to be a driver of HR practices.

The former case might be indicative of a lack of alignment across HR practices in the messages that they send, suggesting that it would be best to revise either the "problematic" HR 
practices themselves or the communication surrounding those HR practices. In the latter case, however, it would be important for management to understand the correlates of those differences in employees' HR attributions. For example, do employees in different locations have different sets of attributions, and with what can those differences be correlated? Employee attributions might diverge due to differences in the way that the HR practices are being implemented across units by managers, for example (Zohar, 2000). In such cases, identifying the particular units in which employee attributions are problematic, and assessing the contextual and managerial factors that may be to blame would be helpful. Depending on the correlates, the interventions likely to be effective will vary. The insights afforded by examining employees' HR attributions, as we just highlighted, suggest that organizations might benefit from expanding the way they view employee attitude surveys. Rather than focusing solely on employees' attitudes (i.e., "engagement"), expanding employee surveys to also focus on employees' perceptions of HR practices would provide more actionable items on which to leverage organizational change efforts.

More generally, based on research which indicates that an effect is attributed to the cause that is most salient to perceivers (McArthur \& Post, 1977; Taylor \& Riske, 1975), it seems it would behoove organizations to communicate the intentions of HR practices to employees in an unambiguous and salient manner, both through formal organizational communications and also more indirectly through line managers. Open communication between managers and their employees should help to not only communicate management's intentions to employees thereby facilitating desired attributions, but also expose the alternative perspectives and attributions that are held by employees so that they can subsequently be addressed by management. An added benefit of increased dialogue between managers and their employees is that it should help align managers' and employees' attributions (Martinko \& Gardner, 1987), thereby reducing the negative outcomes associated with divergent attributions mentioned previously (i.e., reduced satisfaction and increased conflict). 
In addition, given research which suggests there is a primacy bias in the causes to which people attribute events (Jones, et al., 1968; Ross et al., 1975), organizations should pay special attention to the role of recruitment experiences and new employee orientation programs in shaping employees' HR attributions. Generally speaking, when faced with potentially ambiguous stimuli, perceivers scan and interpret available information until an attribution can be made, after which information tends to be disregarded or assimilated into previously made attributions. Thus, employees should be most motivated to seek explanations for HR practices when they first join a company. Differences in the ways that individuals experience entry into the organization may give rise to differential attributions, which, once formed, may be resistant to change in much the same way as other causal schemas (Ross \& Lepper, 1980).

In addition, theories of cognitive homeostasis suggest that experiences with disequilibrium stimulate cognitive reevaluation; thus, organizational change events that alter the organizational landscape are likely to stimulate attributional processes on the part of employees. Indeed, scholars have argued that successful organizational change requires cognitive reframing, or the break-down of old schemas in order to build new schemas that cognitively accommodate the ongoing changes in the external organizational environment (Labianca, Gray, \& Brass, 2000; Sottolano, 2001). This suggests the importance of framing change efforts in ways that stimulate desirable employee attributions regarding the reasons for organizational change (Rousseau \& Tijoriwala, 1999), for these change-related attributions are likely to be closely aligned with employees' re-assessments of their HR attributions.

\section{Limitations}

As with any study, the results of this study must be viewed in light of its limitations. First, it is possible that some of the reported results are inflated by single-source response bias. Nevertheless, there are several reason why we believe that response bias may not be a big concern in the current study. First, we used department manager reports of OCBs rather than employee reports of OCBs in order to control for response bias, and thus only the paths involving the HR Attributions and attitudes may be in question. Second, the construct of HR 
Attributions is conceptually distinct from employee commitment and satisfaction, and thus there is less concern about response bias than there would be if the two constructs being related were highly similar (e.g. positive affect and satisfaction). This was supported by the results of the Harman's one-factor test, which we reported previously. Third, recent literature suggests that common method variance is not as prevalent as researchers once assumed (e.g., Crampton \& Wagner, 1994; Lindell \& Whitney, 2001; Spector, 1987; 1994), and is very seldom a severe enough issue to invalidate research findings (e.g., Doty \& Glick, 1998). Spector (2006), for example, argues that the seemingly automatic criticism of cross-sectional self-report data as being inflated is simply unfounded, as there are few scientific data to unequivocally support the notion that common method alone is sufficient to produce biases, and there is ample data to refute this notion. According to Spector's (2006) reasoning, if common method variance were as serious a problem as some argue, then we should expect to see all variables measured with the same self-report survey to exhibit systematically inflated correlations. In our individual-level data, however, this was not the case. ${ }^{5}$

Another limitation is that because of the cross-sectional nature of the data, questions regarding causality remain unanswered. Thus, for example, it was not possible to test for the possibility that employee attitudes might influence their HR Attributions. It could be, for example, that when people feel dissatisfied with their job and lack organizational identification, they perceive that the organization must not care about them and therefore they make negative attributions about their firm's HR practices. In other words, employees' positive or negative attitudes may provide a lens through which they perceive and attach meaning to organizational activities such as HR practices. Also possible is for customer satisfaction to influence employees' HR Attributions such that high customer satisfaction ratings lead to the attribution that HR practices must be designed with the goal of Service Quality in mind. Future research that incorporates longitudinal data is necessary to test these various alternatives, with perhaps the most likely outcome being that these are reciprocating systems issues (Schneider et al., 1998). 
Indeed, similar criticisms have been made of attribution theories more generally, as most research has treated attributions as being associated with attitudinal consequences in a linear fashion, with attributions influencing attitudes as we have depicted in our model. Some scholars, however, have recognized that the relationship between attributions and their consequences is likely much more cyclical and ongoing, such that properties of an attribution elicit certain attitudes and behaviors that in turn influence subsequent information antecedents of future attributions, often in self-confirming ways (e.g., Kelley \& Michela, 1980). Thus, for example, an employee who is highly committed to an organization and performs many OCBs in response to the attribution that HR practices are motivated by management's concern for quality and employee enhancement may be more likely to elicit attitudes and behaviors on the part of his/her manager that confirm the attribution that management cares for employees. If this were the case, it suggests once more the importance of attending to the HR attributions that are formed during newcomer orientation, as attributions may be difficult to alter once formed. Nevertheless, future research designed to examine the evolving nature of HR attributions over time would be extremely beneficial, both in relation to this specific theory and to attribution theory more generally.

Third, because we chose to test our model within a single organization, we were unable to test the relationship between actual HR practices and HR Attributions. Future research that examines whether HR Attributions play a mediating or moderating role in the relationship between HR practices and organizational performance would be valuable. It may be that certain "high performance work practices" that are internally aligned always lead to certain HR Attributions, in which case HR Attributions would play a mediating role. However, because HR practices are interpreted within the context of a vast array of other organizational information and HR Attributions are influenced by employees' individual cognitions, it is more likely that employees will vary in the attributions that they make for HR practices. This might suggest that the relationship between HR practices and performance is moderated by HR Attributions such 
that only when HR practices are attributed in certain ways do the HR practices lead to organizational performance in desired and expected ways.

Fourth, we were unable to test all of our study hypotheses simultaneously in a single model. Because our independent variables are at the individual-level of analysis and our outcome variables at the department-level, the only viable approach for doing so would have been to test our entire model at the department-level of analysis (Hofmann, Griffin, \& Gavin, 2000). Unfortunately, however, aggregation statistics for the HR attributions did not provide sufficient support for aggregating the attributions to the department level of analysis ${ }^{6}$. We were thus constrained to test our hypotheses using one individual-level and one department-level model.

Finally, the HR practices about which respondents were asked to report in the current study were chosen for their appropriateness in the participating organization. The HR Attribution items may have to be modified for use in other organizations in order to cover the range of HR practices that would be appropriate in those samples. For example, other HR practices of interest might include policies regarding work/family balance or flexible work schedules, performance appraisals, promotion policies, employee assistance programs, and diversity policies. Because we drew from existing SHRM research and piloted our HR attributions with multiple samples, we expect that the construct of HR attributions will be generalizable to other organizations and industries, and that the specific HR attributions that we examined in this study will provide a good foundation for future research. Nevertheless, because people are thought to rely on domain-specific knowledge structures to define likely causes for particular events (Hilton \& Slugoski, 1986), we recognize the possibility that there may be causal explanations, or HR attributions, that are relevant in other organizations and industries that were not for employees in the current organization.

\section{Conclusion}

Despite these limitations, we believe that the results of this study provide important insights into the underlying process by which HR practices become reflected in employee 
attitudes and behaviors, as well as customer satisfaction. As expected based on psychological theories concerning individual differences in cognition, affect, and motivation, employees did not respond uniformly to the same set of HR practices. And while additional research that builds on this study and further explores the notion of HR Attributions is certainly needed, this study provides a useful starting point for future efforts in a similar vein to explore the impact of HR practices on employees and organizations. 


\section{Footnotes}

1. Focus groups with executive managers confirmed the appropriateness of the department, rather than the store, as the unit level of analysis. Many of the organization's structures and activities (e.g., accounting, employee attitude surveys, customer satisfaction measures) are centered on the department rather than the store level of analysis, and employees tend to interact mainly with other employees within their department rather than with members of other departments within their stores. Moreover, a comparison of aggregation statistic indicated that for almost all of the individual level data, $\operatorname{ICC}(1)$ and $r_{w g}$ statistics are considerably higher when aggregating to the department rather than store level of analysis. ICC(2) values, however, which increase with group size (Bliese, 2000) tended to be similar for the department and store levels of analysis.

2. A look at the aggregation statistics for commitment and satisfaction separately suggests that the low ICC-(2) value may be driven in large part by the low ICC-(2) value for the satisfaction item. While the aggregation statistics for affective commitment were all within or close to recommended ranges (the ICC-(1) was .07, the ICC-(2) was .58, and the mean $r_{w g}$ was .53), the values for the single-item measure of satisfaction were lower (the ICC-(1) value was .03, and the ICC-(2) value was 0.33, while the mean $r_{\text {wg }}$ value across departments was .60). The $F$ test for both commitment $\left(F_{(361,2872)}=1.53 ; \underline{\underline{p}}<.01\right)$ and satisfaction $\left(F_{(361,2828)}=1.31 ; \underline{\underline{p}}<.01\right)$ were significant.

3. Non-independence was taken into accout by using the TYPE=COMPLEX analysis command in MPlus, which estimates parameters by maximizing a weighted log likelihood function, and computes standard errors using a sandwich estimator.

4. Past research suggests that the possibility that positive/negative affectivity or cynicism is a universal source of common method variance in self-report data is quite low (Spector, 2006), and that even though negative affectivity may be related to organizational variables, it has little impact on the relations among organizational variables (Chan, 2001; Williams \& Anderson, 1994).

5. If common method bias were this severe a problem, then in our data, we would expect to see all of the $25 \mathrm{HR}$ attribution items, 4 affective commitment items, and the employee satisfaction item to be correlated by virtue of their shared measurement method (i.e., same self-report survey). However, this was not the case; despite very strong power to detect significant differences ( $N=3154-3218$ depending on the analyses), there were 19 correlations among these variables that were not significant, and furthermore, of the correlations that were significant, $42 \%$ of them were smaller than .20 , further suggesting that common method variance is not a universal inflator of correlations (Spector, 2006).

6. For the Quality \& employee enhancement HR attribution, $\operatorname{ICC}(1)=.07, \operatorname{ICC}(2)=.53$ and $\mathrm{r}_{\mathrm{wg}}=.74$; for the Cost \& employee exploitation HR attribution, ICC(1)=.02, ICC(2)=.19, and $r_{w g}=.58$; and for the Union compliance HR attribution, $\operatorname{ICC}(1)=.02, \operatorname{ICC}(2)=.15$, and $r_{w g}=.40$. Not surprisingly, a structural equation model testing all hypotheses simultaneously at the department-level of analysis exhibited poor fit $\left(\mathrm{X}^{2}{ }_{(761)}=1265.87 ; \mathrm{CFI}=.81\right.$; RMSEA=.09; SRMR=.11) 


\section{References}

Antaki, C. (1985). Ordinary explanation in conversation: Causal structures and their defense. European Journal of Social Psychology, 15, 213-230.

Arthur, J.B. (1992). The link between business strategy and industrial relations systems in American steel minimills. Industrial and Labor Relations Review, 45(3), 488-506.

Arthur, J.B. (1994). Effects of human resource systems on manufacturing performance and turnover. Academy of Management Journal, 37, 670-687.

Batt, R. (2002). Managing customer services: Human resource practices, quit rates, and sales growth. Academy of Management Journal, 45(3), 587-597.

Bamberger, P., \& Meshoulam, I. (2000). Human resource strategy: formulation, implementation, and impact. Thousand Oaks, CA: Sage Publications.

Bartko, J.J. (1976). On various intraclass correlation reliability coefficients. Psychological Bulletin, 83, 762-765.

Becker, B.E. \& Gerhart, B. (1996). The impact of human resource management on organizational performance: Progress and prospects. Academy of Management Journal, 39(4), 779-801.

Becker, B.E. \& Huselid, M.A. (1998). High performance work systems and firm performance: A synthesis of research and managerial implications. In G.R. Ferris (Ed.), Research in Personnel and Human Resources Management (p.53-101). Greenwich, CT: JAI Press.

Bentler, P.M., \& Chou, C.P. (1988). Practical issues in structural modeling. In J.S. Long (Ed.), Common Problems/proper solutions: Avoiding error in survey research (pp.161-192). Newbury Park, CA: Sage.

Bliese, P.D. (2000). Within-group agreement, non-independence, and reliability: Implications for data aggregation and analysis. In K.J. Klein \& S.W.J. Kozlowski (Eds.), Multilevel theory, research, and methods in organizations: Foundations, extensions, and new directions (pp.349-381). San Francisco, CA: Jossey-Bass.

Bowen, D.E., \& Ostroff, C. (2004). Understanding HRM-firm performance linkages: The role of the "strength" of the HRM system. Academy of Management Review, 29(2), 203-221.

Bruner, J.S. (1957). Going beyond the information given. In H. Gruber, K. Hammond, \& R. Jesser (eds.), Contemporary approaches to cognition (pp.41-69). Cambridge, MA: Harvard University Press.

Chan, D. (1998). Functional relations among constructs in the same content domain at different levels of analysis: A typology of compsotion models. Journal of Applied Psychology, 83, 234-246.

Chan, D. (2001). Method effects of positive affectivity, negative affectivity, and impression management in self-reports of work attitudes. Human Performance, 14, 77-96.

Child, J. (1972). Organizational structure, environment and performance: The role of strategic choice. Sociology, 6, 1-22.

Child, J. (1997). Strategic choice in the analysis of action, structure, organizations and environment: Retrospect and prospect. Organization Studies, 18, 43-76.

Crampton, S.M., \& Wagner, J.A., III. (1994). Percept-percept inflation in microorganizational research: An investigation of prevalence and effect. Journal of Applied Psychology, 79, 67-76.

Currall, S.C., Towler, A.J., Judge, T.A., \& Khon, L. (2005). Pay satisfaction and organizational outcomes. Personnel Psychology, 58, 613-640.

Deckop, J.R., Mangel, R. \& Cirka, C.C. (1999). Getting more than you pay for: Organizational citizenshihp behavior and pay-for-performance plans. Academy of Management Journal, 42(4), 420-428. 
Delery, J.E. \& Doty (1996). Modes of theorizing in strategic human resource management: Tests of universalistic, contingency, and configurational performance predictions. Academy of Management Journal, 39, 802-835.

Delery, J.E. (1998). Issues of fit in strategic human resource management: Implications for research. Human Resource Management Review, 8, 289-310.

Doty, D.H., \& Glick, W.H. (1998). Common method bias: Does common methods variance really bias results? Organizational Research Methods, 1, 374-406.

Dunham, R.B. \& Herman, J.B. (1975). Development of a female faces scale for measuring job satisfaction. Journal of Applied Psychology, 60, 629-631.

Eagly, A., \& Chaiken, S. (1993). Psychology of attitudes. NY: Harcourt, Brace Jovanovich.

Ehrhart, M.G. \& Naumann, S.E. (2004). Organizational citizenship behavior in work groups: A group norms approach. Journal of Applied Psychology, 89(6), 960-974.

Eisenberger, R., Fasolo, P., \& Davis-LaMastro, V. (1990). Perceived organizational support and employee diligence, commitment, and innovation. Journal of Applied Psychology, 75(1), 51-59.

Frese, M. (1985). Stress at work and psychosomatic complaints: A causal interpretation. Journal of Applied Psychology, 70, 314-328.

Golding, S.L. \& Rorer, L.G. (1972). Illusory correlation and subjective judgment. Journal of Abnormal Psychology, 80, 249-260.

Graen, G.B. \& Uhl-Bien, M. (1995). Development of LMX theory of leadership over 25 years: Applying a multi-level multi-domain perspective. Leadership Quarterly, 6, 210-247.

Gutek, B.A., \& Winter, S.J. (1992). Consistency of job satisfaction across situations: Fact or framing artifact? Journal of Vocational Behavior, 41, 61-78.

Hamilton, V.L. (1980). Intuitive psychologist or intuitive lawyer? Alternative models of the attribution process. Journal of Personality and Social Psychology, 39, 767-772.

Harter, J.K., Schmidt, F.L., \& Hayes, T.L. (2002). Business-unit-level relationship between employee satisfaction, employee engagement, and business outcomes: A meta-analysis. Journal of Applied Psychology, 87(2), 268-279.

Heskett, J.L., Sasser, W.E., \& Schlesinger, L.A. (1997). The service profit chain: How leading companies link profit and growth to loyalty, satisfaction, and value. New York, NY: The Free Press.

Heider, F. (1958). The psychology of interpersonal relation. New York: Wiley.

Hilton, D.J., \& Slugoski, B.R. (1986). Knowledge-based causal attribution: The abnormal conditions focus model. Psychological Review, 93, 75-88.

Huselid, M.A. (1995). The impact of human resource management practices on turnover, productivity, and corporate financial performance. Academy of Management Journal, 38(3), 635-672.

Ichheiser, G. (1949). Misunderstandings in human relations: A study in false social perception. American Journal of Sociology, 55.

Ironson, G.H., Smith, P.C., Brannick, M.T., Gibson, W.M., \& Paul, K.B. (1989). Construction of a job in general scale: A comparison of global, composite, and specific measures. Journal of Applied Psychology, 74, 193-200.

Jackson, S.E., \& Schuler, R.S. (1995). Understanding human resource management in the context of organizations and their environments. Annual Review of Psychology, 46, 237264.

James, L.R. (1982). Aggregation bias in estimates of perceptual agreement. Journal of Applied Psychology, 67, 219-229.

James, L.R., Demaree, R.G., \& Wolf, G. (1984). Estimating within-group interrater reliability with and without response bias. Journal of Applied Psychology, 69, 85-98.

James, L.R., Joyce, W.F., \& Slocum, J.W. (1988). Organizations do not cognize. Academy of Management Review, 13(1), 129-132. 
Jones, E.E., \& Davis, K.E. (1965). From acts to dispositions: The attribution process in person perception. In L. Berkowitz (Ed.), Advances in experimental social psychology, Vol. 2 (pp.219-266). New York: Academic Press.

Jones, E.E., Kanouse, D.E., Kelley, H.H., Nisbett, R.E., Valins, S., \& Weinder, B. (Eds.) (1972). Attribution: Perceiving the causes of behavior. Morristown, NJ: General Learning Press.

Jones, E.E., \& McGillis, D. (1976). Correspondent inferences and the attribution cube: A comparative reappraisal. In J.H. Harvey, W.J. Ickes, \& R.F. Kidd (Eds.), New directions in attribution research (Vol. 1, pp. 189-420). Hillsdale, NJ: Erlbaum.

Jones, E.E., \& Nisbett, R.E. (1972). The actor and the observer: Divergent perceptions of the causes of behavior. In E.E. Jones, D.E. Kanouse, H.H. Kelley, R.E. Nisbett, S.Valins, \& B. Weiner (Eds.), Attributions: Perceiving the causes of behavior (pp.79-94). Morristown, NJ: General Learning Press.

Jones, E.E., Rock, L., Shaver, K.G., Goethals, G.R., \& Ward, L.M> (1968). Pattern of performance and ability attribution: An unexpected primacy effect. Journal of Personality and Social Psychology, 10, 317-340.

Judge, T.A., Thoresen, C.J., Bono, J.E., \& Patton, G.K. (2001). The job satisfaction-job performance relationship: A qualitative and quantitative review. Psychological Bulletin, 127(3), 376-407.

Kelley, H.H. (1967). Attribution theory in social psychology. In D.Levine (Ed.), Nebraska Symposium on Motivation (Vol. 15, pp.192-240). Lincoln: University of Nebraska Press.

Kelley, H.H. (1973). The process of causal attribution. American Psychologist, 28, 107-128.

Kelley, H.H. \& Michela, J.L. (1980). Attribution theory and research. Annual Review of Psychology, 31, 457-501.

Kozlowski, S.W.J. \& Hattrup, K. (1992). A disagreement about within-group agreement: Disentagling issues of consistency versus consensus. Journal of Applied Psychology, 77, 161-167.

Kozlowski, S.W.J \& Klein, K.J. (2000). A multilevel approach to theory and research in organizations: Contextual, temporal, and emergent processes. In K.J. Klein \& S.W.J. Kozlowski (Eds.), Multilevel theory, research, and methods in organizations: Foundations, extensions, and new directions (pp.3-90). San Francisco, CA: Jossey-Bass, Inc.

Koys, D.J. (1988). Human resource management and a culture of respect: Effects of employees' organizational commitment. Employee Rights and Responsibilities Journal, 1, 57-68.

Koys, D.J. (1991). Fairness, legal compliance, and organizational commitment. Employee Rights and Responsibilities Journal, 4(4), 283-291.

Lepak, D.P., Taylor, M.S., Tekleab, A., \& Marrone, J. (2002). Firms' use of high investment HR systems to manage employees for competitive advantage: Differential use and implications for performance. Presented at the annual conference for the Academy of Management, Denver, CO.

Lindell, M.K., \& Whitney, D.J. (2001). Accounting for common method variance in cross-sectional research designs. Journal of Applied Psychology, 86, 114-121.

Lord, R.G. \& Smith, J.E. (1983). Theoretical, information processing, and situational factors affecting attribution theory models of organizational behavior. Academy of Management Review, 8(1), 50-60.

Martinko, M.J., \& Gardner, W.L. (1987). The leader-member attribution process. Academy of Management Review, 12(2), 235-249.

McArthur, L.Z., \& Post, D.L. (1977). Figural emphasis and person perception. Journal of Experimental Social Psychology, 13, 520-535.

Meyer, J.P., \& Allen, M.J. (1997). Commitment in the workplace: Theory, research and application. Thousand Oaks, CA: Sage Publications. 
Meyer, J.P, Allen, M.J., \& Smith, C.A. (1993). Commitment to organizations and occupations: Extension and test of a three-component conceptualization. Journal of Applied Psychology, 78, 538-551.

Mischel, W., \& Shoda, Y. (1995). A cognitive-affective system theory of personality: Reconceptualizing situations, dispositions, dynamics, and invariance in personality structure. Psychological Review, 102(2), 246-268.

Moregson, F.P., \& Hoffman, D.A. (1999). The structure and function of collective constructs: Implications for multilevel research and theory development. Academy of Management Review, 24, 249-265.

Morrison, E.W. (1997). Service quality: An organizational citizenship behavior framework. Advances in the Management of Organizational Quality, 2, 211-249.

Nishii, L.H., \& Wright, P. (In press). Variability at multiple levels of analysis: Implications for strategic human resource management. In D.B. Smith (Ed.), The people make the place. Mahwah, NJ: Lawrence Erlbaum Associates.

Organ, D.W. (1997). Organizational citizenship behavior: It's construct clean-up time. Human Performance, 10(2), 85-97.

Organ, D.W., Podsakoff, P.M. \& MacKenzie, S.B. (2005). Organizational citizenship behavior: Its nature, antecedents, and consequences. Thousand Oaks, CA: Sage Publications.

Osterman, P. (1994). How common is workplace transformation and how adopts it? Industrial and Labor Relations Review, 47, 173-188.

Ostroff, C. (1992). The relationship between satisfaction, attitudes, and performance: An organizational level analysis. Journal of Applied Psychology, 77, 963-974.

Ostroff, C. \& Bowen, D.E. (2000). Moving HR to a higher level: Hr practices and organizational effectiveness. In K.J. Klein \& S.W.J. Kozlowski (Eds.), Multilevel theory, research, and methods in organizations: Foundations, extensions, and new directions (pp.211-266). San Francisco, CA: Jossey-Bass, Inc.

Podsakoff, P.M., MacKenzie, S.B., Moorman, R.H., \& Fetter, R. (1990). Transformational leader behaviors and their effects on followers' trust in leader, satisfaction, and organizational citizenship behaviors. The Leadership Quarterly, 1(2), 1048-9843.

Porter, M. E. (1996). What is strategy? Harvard Business Review, November-December, 61-78.

Rentsch, J.R. (1990). Climate and culture: Interaction and qualitative differences in organizational meanings. Journal of Applied Psychology, 75(6), 668-681.

Ross, M. \& Fletcher, G.J.O. (1985). Attribution and social perception. In G. Lindzey \& E. Aronson (Eds.), The handbook of Social Psychology, Vol. 2. New York: Random House.

Ross, L., \& Lepper, M.R. (1980). The perseverance of beliefs: Empirical and normative considerations. In R.A. Shweder \& D. Fiske (Eds.), New directions for methodology of behavioral science: Fallible judgment in behavioral research (pp.17-36). San Francisco: Jossey-Bass.

Schmit, M.J., \& Allscheid, S.P. (1995). Employee attitudes and customer satisfaction: Making theoretical and empirical connection. Personnel Psychology, 48, 521-536.

Schneider, B. (1987). The people make the place. Personnel Psychology, 40, 437-454.

Schneider, B., \& Bowen, D.E. (1995). Winning the service game. Boston, MA: Harvard Business School Press. Burke \& C. Cooper (Eds.). Reinventing Human Resources. London: Routledge.

Schneider, B., Ehrhart, M.G., Mayer, D.M., Saltz, J.L., \& Niles-Jolly, K. (2005). Understanding organization-customer links in service settings. Academy of Management Journal, 48(6), 1017-1032.

Schneider, B., Salvaggio, A.N., \& Subirats (2002). Climate strength: A new direction for climate research. Journal of Applied Psychology, 87(2), 220-229. 
Schneider, B., Hanges, P.J., Smith, S.B., \& Salvaggio, A.N. (2003). Which comes first: Employee attitudes or organizational financial and market performance? Journal of Applied Psychology, 88(5), 836-851.

Schneider, B., \& White, S.S. (2004). Service quality: Research perspectives. Thousand Oaks, CA: Sage Publications.

Schuler, R.S., \& Jackson, S.E. (1987). Linking competitive strategies with human resource management practices. Academy of Management Executive, 1(3), 207-219.

Shore, L.M., \& Wayne, S.J. (1993). Commitment and employee behavior: Comparison of affective commitment and continuance commitment with perceived organizational support. Journal of Applied Psychology, 78, 774-780.

Sorensen, J.B. (2002). The strength of corporate culture and reliability of firm performance. Administrative Science Quarterly, 47, 70-91.

Spector, P.E. (1987). Method variance as an artifact in self-reported affect and perceptions at work: Myth or significant problem? Journal of Applied Psychology, 72, 438-443.

Spector, P.E. (1994). Using self-report questionnaires in OB research: A comment on the use of controversial method. Journal of Organizational Behavior, 15, 385-392.

Spector, P.E. (2006). Method variance in organizational research: Truth or urban legend? Organizational Research Methods, 9(2), 221-232.

Spreitzer, G.M. (1995). Psychological empowerment in the workplace: dimensions, measurement, and validation. Academy of Management Journal, 38(5), 1442-1465.

Tsui, A.S., Pearce, J.L., Porter, L.W., \& Hite, J.P. (1995). Choice of employee-organization relationship: Influence of external and internal organizational factors. In G.R. Ferris (Ed.), Research in Personnel and Human Resources Management (pp.117-151). Greenwich, CT: JAI Press.

Tsui, Pearce, Porter, \& Tripoli (1997). Alternative approaches to the employee-organization relationship: Does investment in employees pay off? Academy of Management Journal, 40(5), 1089-1121.

Wanous, J.P., Reichers, A.E., \& Hudy, M.J. (1997). Overall job satisfaction: How good are single-item measures? Journal of Applied Psychology, 82(2).

Weick, K.E. (1985). The significance of corporate culture.

Weick, K.E. (1995). Sensemaking in organizations. Thousand Oaks: CA: Sage Publications.

Weiner, B., Frieze, I., Kukla, A., Reed, L., Rest, S., \& Rosenbaum, R.M. (1972). Perceiving the causes of success and failure. New York: General Learning Press.

Wexley, K.N., Alexander, R.A., Greenawalt, J.PI, \& couch, M.A. (1980). Attitudinal congruence and similarity as related to interpersonal evaluations in manager-subordinate dyads. Academy of Management Journal, 23, 320-330.

Whitener, E.M. (2001). Do "high commitment" human resource practices affect employee commitment? A cross-level analysis using hierarchical linear modeling. Journal of Management, 27, 515-535.

Williams, L.J., \& Anderson, S.E. (1994). An alternative approach to method effects using latentvariable models: Applications in organizational behavior research. Journal of Applied Psychology, 79, 323-331.

Wright, P.M., \& Boswell, W.R. (2002). Desegregating HRM: A review and synthesis of micro and macro human resource management research. Journal of Management, 28(3), 247-276.

Wright, P.M., \& Nishii, L.H. (in press). Strategic HRM and organizational behavior: Integrating multiple levels of analysis. In D. Guest (Ed.), Innovations in HR.. Oxford: Blackwell Publishing.

Zwick, W.R., \& Velicer, W.F. (1982). Factors influencing four rules for determining the number of components to retain. Multivariate Behavioral Research, 17, 253-269. 


\section{Appendix 1}

\section{HR Attribution scale items}

Directions: In this section, we would like to know your opinions about why your company has the personnel policies and practices it has. Please tell us the extent to which you agree with each of the statements below.

[Company name] provides employees the training that it does:

1. in order to help employees deliver quality service to customers.

2. so that employees will feel valued and respected-to promote employee well-being.

3. to try to keep costs down.

4. because they are required to by the union contract.

5 . in order to get the most work out of employees.

[Company name] provides employees the benefits that it does (e.g., health care, retirement plans):

1. in order to help employees deliver quality service to customers.

2. so that employees will feel valued and respected-to promote employee well-being.

3. to try to keep costs down.

4. because they are required to by the union contract.

5 . in order to get the most work out of employees.

[Company name] makes the hiring choices that it does (i.e., the number and quality of people hired):

1. in order to help employees deliver quality service to customers.

2. so that employees will feel valued and respected-to promote employee well-being.

3. to try to keep costs down.

4. because they are required to by the union contract.

5 . in order to get the most work out of employees.

[Company name] pays its employees what it does:

1. in order to help employees deliver quality service to customers.

2. so that employees will feel valued and respected-to promote employee well-being.

3. to try to keep costs down.

4. because they are required to by the union contract.

5 . in order to get the most work out of employees.

[Company name] schedules employees the way it does (hours, flexibility, leave policies):

1 . in order to help employees deliver quality service to customers.

2. so that employees will feel valued and respected-to promote employee well-being.

3. to try to keep costs down.

4. because they are required to by the union contract.

5 . in order to get the most work out of employees. 